NUREG/CR-4294 85-ETEC-DRF-1714

\title{
Leak Rate Analysis of the Westinghouse Reactor Coolant Pump
}

\section{DO NOT MICROFILM \\ COVER}

Prepared by T. Boardman, N. Jeanmougin, R. Lofaro, J. Prevost

Energy Technology Engineering Center

Prepared for

U.S. Nuclear Regulatory

Commission 


\section{DISCLAIMER}

This report was prepared as an account of work sponsored by an agency of the United States Government. Neither the United States Government nor any agency Thereof, nor any of their employees, makes any warranty, express or implied, or assumes any legal liability or responsibility for the accuracy, completeness, or usefulness of any information, apparatus, product, or process disclosed, or represents that its use would not infringe privately owned rights. Reference herein to any specific commercial product, process, or service by trade name, trademark, manufacturer, or otherwise does not necessarily constitute or imply its endorsement, recommendation, or favoring by the United States Government or any agency thereof. The views and opinions of authors expressed herein do not necessarily state or reflect those of the United States Government or any agency thereof. 


\section{DISCLAIMER}

Portions of this document may be illegible in electronic image products. Images are produced from the best available original document. 


\section{NOTICE}

This report was prepared as an account of work sponsored by an agency of the United States Government. Neither the United States Government nor any agency thereof, or any of their employees, makes any warranty, expressed or implied, or assumes any legal liability of responsibility for any third party's use, or the results of such use, of any information, apparatus, product or process disclosed in this report, or represents that its use by such third party would not infringe privately owned rights.

\section{DO NOT MICROFILM COVER}

\section{NOTICE}

\section{Availability of Reference Materials Cited in NRC Publications}

Most documents cited in NRC publications will be available from one of the following sources:

1. The NRC Public Document Room, 1717 H Street, N.W. Washington, DC 20555

2. The Superintendent of Documents, U.S. Government Printing Office, Post Office Box 37082 , Washington, DC 20013-7082

3. The National Technical Information Service, Springfield, VA 22161

Although the listing that follows represents the majority of documents cited in NRC publications, it is not intended to be exhaustive.

Referenced documents available for inspection and copying for a fee from the NRC Public Docu. ment Room include NRC correspondence and internal NRC memoranda; NRC Office of Inspection and Enforcement bulletins, circulars, information notices, inspection and investigation notices; Licensee Event Reports; vendor reports and correspondence; Commission papers; and applicant and licensee documents and correspondence.

The following documents in the NUREG series are available for purchase from the NRC/GPO Sales Program: formal NRC staff and contractor reports, NRC-sponsored conference proceedings, and NRC booklets and brochures. Also available are Regulatory Guides, NRC regulations in the Code of Federal Regulations, and Nuclear Regulatory Commission /ssuances.

Documents available from the National Technical Information Service include NUREG series reports and technical reports prepared by other federal agencies and reports prepared by the Atomic Energy Commission, forerunner agency to the Nuclear Regulatory Commission.

Documents available from public and special technical libraries include all open literature items, such as books, journal and periodical articles, and transactions. Federal Register notices, federal and state legislation, and congressional reports can usually be obtained from these libraries.

Documents such as theses, dissertations, foreign reports and translations, and non-NRC conference proceedings are available for purchase from the organization sponsoring the publication cited.

Single copies of NRC draft reports are available free, to the extent of supply, upon written request. to the Division of Technical Information and Document Control, U.S. Nuclear Regulatory Commission, Washington, DC 20555.

Copies of industry codes and standards used in a substantive manner in the NRC regulatory process are maintained at the NRC Library, 7920 Norfolk Avenue, Bethesda, Maryland, and are available there for reference use by the public. Codes, and standards are usually copyrighted and may be purchased from the originating organization or, if they are American National Standards, from-the American National Standards Institute, 1430 Broadway, New York, NY 10018. 


\section{Leak Rate Analysis of the Westinghouse Reactor Coolant Pump}

NUREG/CR--4294

TI85 901844

Manuscript Completed: January 1985

Date Published: July 1985

\section{Prepared by}

T. Boardman, N. Jeanmougin, R. Lofaro, J. Prevost

Energy Technology Engineering Center

Rockwell International Corporation

P.O. Box 1449

Canoga Park, CA 91304

\section{Prepared for}

Division of Engineering Technology

Office of Nuclear Regulatory Research

U.S. Nuclear Regulatory Commission

Washington, D.C. 20555

NRC FIN B3049

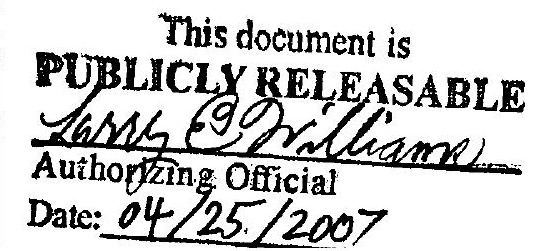




\section{NOTICE}

This report was prepared as an account of work sponsored by an agency of the United States Government. Neither the United States Government nor any agency thereof, or any of their employees. makes any wartanty, expressed or implied, or assumes any legal liability of re. sponsibility for any third party's use, of the results of such use, of any information, apparatus. product or process disclosed in this report. or represents that its use by such third party would not intringe privately owned rights.

\section{NOTICE}

Availability of Reference Materials Cited in NRC Publications

Most documents cited in NRC publications will be available from one of the following sources:

1. The NRC Public Document Room, 1717 H Street, N.W. Washington, DC 20555

2. The NRC/GPO Sales Program, U.S. Nuclear Regulatory Commission. Washington, DC 20555

3. The National Technical Information Service. Springfield, VA 22161

Although the listing that follows represents the majority of documents cited in NRC publications, it is not intended to be exhaustive.

Referenced documents available for inspection and copying for a fee from the NRC Public Docu. ment Room include NRC correspondence and internal NRC memoranda: NRC Office of Inspection and Enforcement bulletins, circulars, information notices, inspection and investigation notices; Licensee Event Reports; vendor reports and correspondence; Commission papers; and applicant and licensee documents and correspondence.

The following documents in the NUREG series are available for purchase from the NRC/GPO Sales Program: formal NRC staff and contractor reports, NRC.sponsored conference proceedings, and NRC booklets and brochures. Also available are Regulatory Guides, NRC regulations in the Code of Federal Regulations, and Nuclear Regulatory Commission Issuances.

Documents available from the National rechnical Information Service include NUREG series reports and technical reports prepared by other federal agencies and reports prepared by the Atomic Energy Commission, forerunner agency to the Nuclear Regulatory Commission.

Documents available from public and special technical libraries include all open literature items, such as books, journal and periodical articles, and transactions. Federal Register notices, federal and state legislation, and congressional reports can usually be obtained from these libraries.

Documents such as theses, dissertations, foreign reports and translations, and non-NAC conference proceedings are available for purchase from the organization sponsoring the publication cited.

Single copies of NRC draft reports are available free, to the extent of supply, upon written request to the Division of Technical Information and Document Control, U.S. Nuclear Regulatory Com. mission. Washington, DC 20555.

Copies of industry codes and standards used in a substantive manner in the NRC regulatory process are maintained at the NRC Library, 7920 Norfolk Avenue, Bethesda, Maryland, and are available there for reference use by the public. Codes and standards are usually copyrighted and may be purchased from the originating organization or, if they are American National Standards, from the American National Standards Institute, 1430 Broadway, New York, NY 10018. 


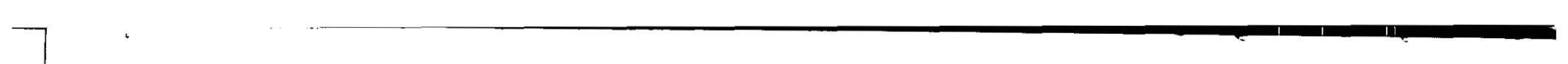


An independent analysis was performed by ETEC to determine what the seal leakage rates would be for the Westinghouse Reactor Cool ant Pump (RCP) during a postulated station blackout resulting from loss of ac electric power. The object of the study was to determine leakage rates for the following conditions:

Case 1: All three seals function.

Case 2: No. 1 seal fails open while Nos. 2 and 3 seals function.

Case 3: All three seals fail open.

The ETEC analys is confirmed Westinghouse calculations on RCP seal performance for the conditions investigated. The leak rates predicted by ETEC were slightly lower than those predicted by Westinghouse for each of the three cases as summarized below.

Case 1: ETEC predicted $19.6 \mathrm{gpm}$, Westinghouse predicted $21.1 \mathrm{gpm}$.

Case 2: ETEC predicted $64.7 \mathrm{gpm}$, Westinghouse predicted $75.6 \mathrm{gpm}$.

Case 3: ETEC predicted $422 \mathrm{gpm}$, Westinghouse predicted $480 \mathrm{gpm}$. 

ABSTRACT....................................

EXECUTIVE SUMMARY.......................... 1

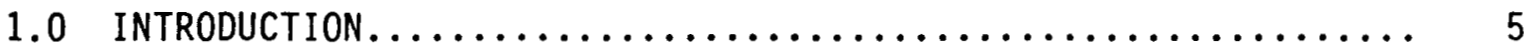

2.0 MODELS...................................... 6

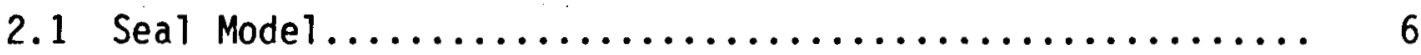

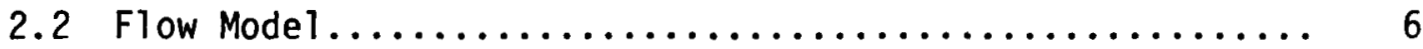

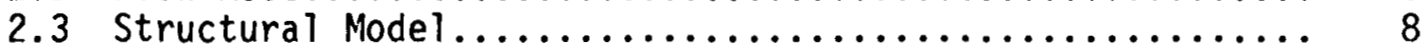

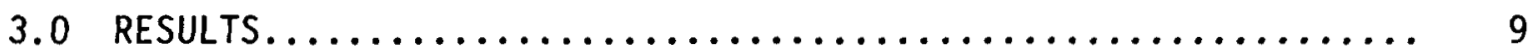

3.1 All Three Seals Function....................... 9

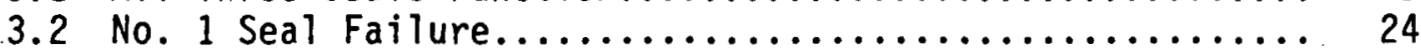

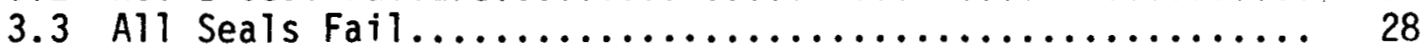

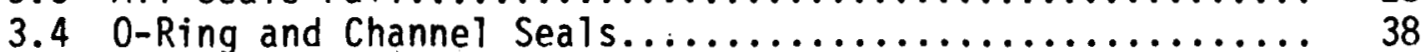

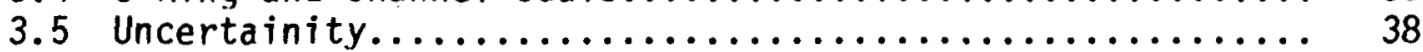

4.0 CONCLUSIONS AND RECOMMENDATIONS ................... 42

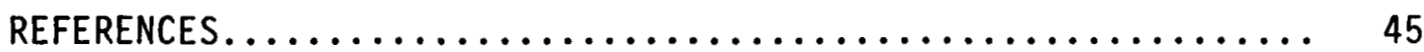

APPENDIX A: Seal Force Balance Model............... 46

APPENDIX B: Flow Model $\ldots \ldots \ldots \ldots \ldots \ldots \ldots \ldots \ldots \ldots \ldots \ldots \ldots$ 


\section{FIGURES}

Page

1. RCP Seal Assembly................................ 2

2. \#1 Film Riding Seal Force Balance.................... 7

3. Comparative Leakage Rates......................... 10

4. Decrease in \#1 Seal Angle vs Delta Pressure............. 11

5. Increase in \#1 Seal Angle vs Delta Pressure............. 12

6. Isotherm Map of \#1 Seal............................ 14

7. Isotherm Map of $\$ 2$ Seal.......................... 16

8. Reactor Coolant System Pressure vs Time -Operator Initiated Cooldown.......................... 17

9. Reactor Coolant System Temperature vs. Time -Operator Initiated Cooldown........................... 18

10. Assumulated Leakage vs Time -- All Seals Function........ 20

11. Reactor Coolant System Pressure vs Time .- No Cooldown.... 21

12. Reactor Coolant System Temperature vs Time -- No Cooldown. 22

13. Isotherm Map of \#1 Seal -- Isothermal Faceplates......... 25

14. Isotherm Map of \#1 Seal -- No Heat Transfer Across Faceplate........................................ 26

15. Accumulated Leakage vs Time -- \#1 Seal Failed, \#2 and \#3 Seals Function..................................... 31

16. Typical \#1 Seal Leakoff Piping..................... 32

17. Typical \#1 Seal Leakoff Piping - Modification $1 . . . . . . . . .33$

18. Typical \#1 Seal Leakoff Piping - Modification 2......... 34

19. Leakage vs \#1 Leakoff Line Resistance................ 35

20. Leakage vs. Labyrinth Seal Resistance............... 37

21. 0-Ring and Channel Seals -. \#1 Seal Assembly........... 40

22. Isotherm Map of $\$ 2$ Seal.......................... 41 


\section{TABLES}

Page

1. Leakage Rates During Reactor Coolant System Cooldown --

All Seals Function.............................

2. Leakage Rates Without Reactor Coolant System Cooldown --

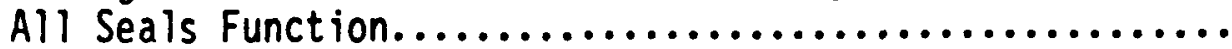

3. Leakage Rates During Reactor Coolant System Cooldown --

$\# 1$ Seal Fails, \#2 and $\# 3$ Seals Function................

4. Leakage Rates Without Reactor Coolant System Cooldown --

\# Seal Fails, \#2 and \#3 Seals Function................

5. O-Ring and Channel Seal Gland Gap Changes -. \#1 Seal

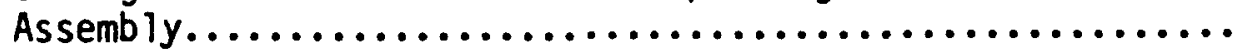

6. Leakage Rates at Initial Reactor Coolant System

Conditions..................................... 


\section{EXECUTIVE SUMMARY}

This work was performed by the Energy Technology Engineering Center (ETEC) in response to Nuclear Regulatory Commission (NRC) concerns regarding leakage rates of the Westinghouse Reactor Coolant Pump (RCP) during station blackout. The object of the study is to independently determine leakage.rates for the postulated functional state of the assembly without consideration to predicting failure or identifying the failure mechanism. During the loss of ac electric power the pump would be stationary and all cooling functions would be lost. It was assumed that pump rotation stops immediately after a station blackout occurs.

Figure 1 is a schematic of the RCP seal assembly. The RCP is a vertical shaft pump with three seals. The no. 1 seal is a film-riding, controlled, leakage seal. The no. 2 and 3 seals are rubbing face type.

The scope of the study includes leakage rate predictions for the following cases.

1. All three seals function.

2. No. 1 seal fails open while no. 2 and 3 seals function.

3. All three seals fail open.

The analysis also addresses the following concerns:

1) effect of system cooldown and depressurization on leakage rates

2) sensitivity of leakage to dimensional and thermal hydraulic parameters.

Force balance equations were developed for the no. 1 seal faceplates to predict seal gap, pressure drop and flow. Finite element structural models were developed for all three seals to predict thermal and pressure distortions. Two-phase flow correlations based on the Dukler constant slip flow model were used to determine seal leakage. The flow model included the following assumptions:

1) thermodynamic equilibrium between phases

2) adiabatic process

3) uniaxial steady state flow.

Results of the independent ETEC analys is confirm Westinghouse calculations on seal performance for the conditions investigated.

1. An initial leakage rate of $19.6 \mathrm{gpm}$ was calculated for the case with all three seals functioning.

2. An initial leakage rate of $64.7 \mathrm{gpm}$ was predicted for the case with no. 1 seal failure and no. 2 and 3 seals functional. 


\section{FIGURE 1: RCP SEAL ASSEMBLY}

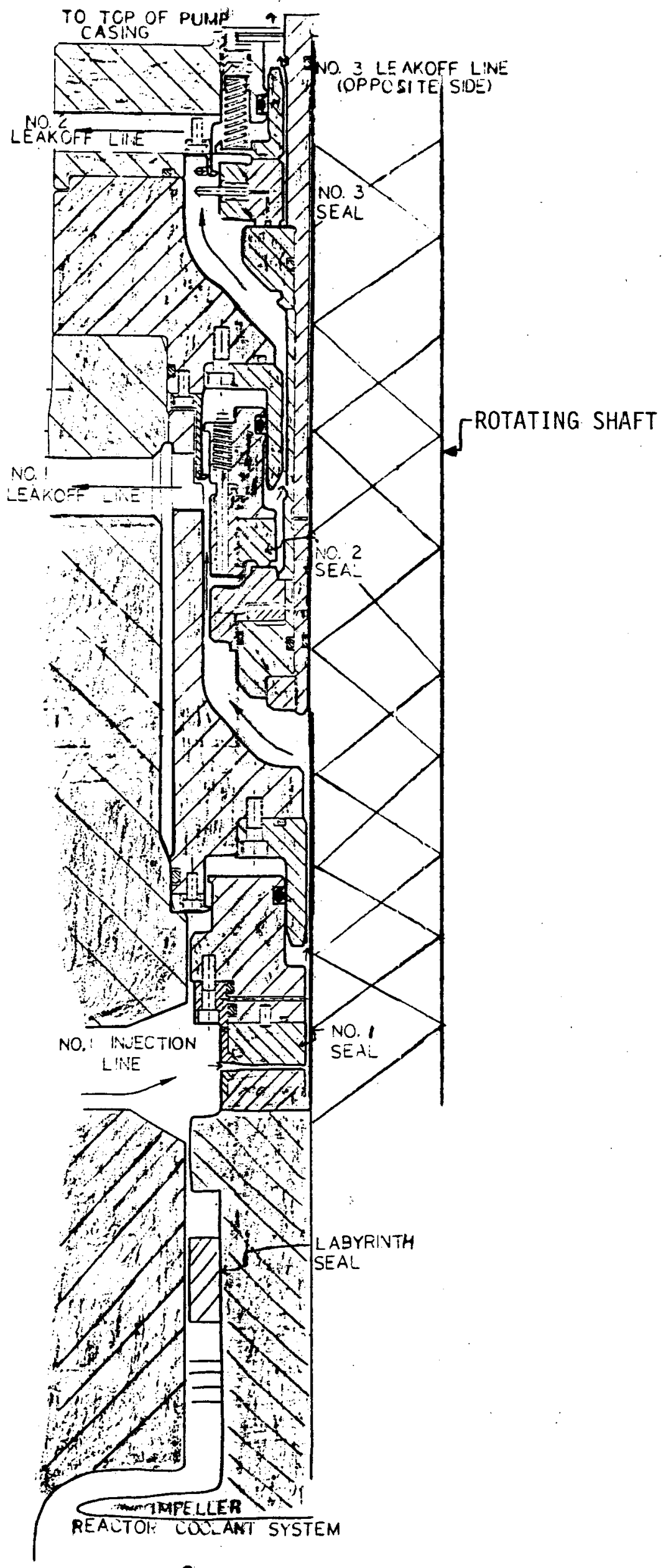


3. An initial leakage rate of $422 \mathrm{gpm}$ was calculated for the case with all three seals failed.

4. The no. 2 seal will rotate closed if the no. 1 seal fails.

5. Leakage rates decrease due to reactor depressurization (2250 psia to 1250 psia)
a. $19.6 \mathrm{gpm}$ decreases to $16.9 \mathrm{gpm}$
b. $64.7 \mathrm{gpm}$ decreases to $33.7 \mathrm{gpm}$.

The following recommendations are made regarding future investigation.

1. Determine Experimentally the Probability of Seal Failure

Analys is indicates that seal failure is an important factor in determining the time required to uncover the core. The probability of seal failure cannot be accurately determined by analysis, therefore the probability of seal failure should be determined experimentally.

2. Evaluate the Effect of Boil-Off Downstream of No. 2 Seal

ETEC and Westinghouse analyses predict that the temperature gradient across the No. 2 seal will cause it to rotate closed during a station blackout. However, if all the water downstream of the no. 2 seal flashes to steam and "boils-off," the heat sink provided by the water will be lost and the temperature gradient across the no. 2 seal will decrease. The predicted leakage rate is close to the boil-off rate, therefore an analysis of the no. 2 seal, assuming boil-off, would provide valuable information on seal stability and closure.

3. Determine Experimentally the Labyrinth Seal Flow Resistance

The dominant resistance for the case when all three seals fails is the labyrinth seal located between the impeller and the first stage seal. To identify the worst case leakage rate when all three seals fail open, the resistance factor for the labyrinth should be determined experimentally.

4. Evaluate Time to Uncover Core for Specific Plants

An important result of the leakage rate analys is is the time required to uncover the core. This time should be determined for specific plants based on their individual system thermal hydraulic response characteristics and hardware designs.

5. Evaluate No. 2 Seal Leakage with Failure of No. 1 Seal

Analysis indicates that the no. 2 seal will rotate closed during a station blackout due to thermal gradients across the seal. This behavior limits the overall leak rate, especially if the no. 1 seal 
fails open. As presented in section 3.2.1, the calculated leak rate past the no. 2 seal when it rotates closed is on the order of $1 \mathrm{gpm}$. However, analys is can not verify whether the no. 2 seal can withstand full system pressure and high temperature gradients for an extended time period. Therefore, testing of the no. 2 seal subjected to these conditions--preferrably during a test of a full scale seal assembly-is recommended. If testing of a RCP seal assembly is not conducted; then tests of the 0-rings and channel seals, under pressure and temperature conditions which would exist if the no. 1 seal failed, should be considered. 


\subsection{INTRODUCTION}

The Energy Technology Engineering Center. (ETEC) conducted an independent analys is of the leakage rates from the primary coolant system through the Westinghouse Reactor Coolant Pump (RCP) shaft seals and associated downstream piping for a postulated station blackout condition. A station blackout would cause loss of ac power to the $P$ lant, loss of RCP rotation, and loss of cooling and injection water to the RCP seal system subjecting the seals to off-design conditions. There is concern that leakage through the RCP seal system would cause the core to be uncovered during a lengthy station blackout. The ETEC study was funded by the Nuclear Regulatory Commission (NRC) as a part of the research on this issue. Proprietary documents detailing the RCP dimensions and construction were provided by Westinghouse but are not included as part of this report.

The scope of the study encompassed prediction of leakage rates during a proposed station blackout for the following cases.

1. All three seals function.

2. The no. 1 seal fails open while the nos. 2 and 3 seals function.

3. All three seals fail open.

Leakage was calculated for nominal reactor coolant system conditions (2250 psia and $550^{\circ} \mathrm{F}$ ) during normal plant operation. The effect of reactor coolant system (RCS) depressurization and cooldown on leakage was also investigated. In addition, the sensitivity of the calculated leakage rates to changes in various parameters was evaluated. 


\subsection{MODELS}

The computer models developed for calculating the leakage rates were, 1) a seal model, 2) a flow model, and 3) a structural model. The seal model determines the gap and pressure distribution between the faceplates of the no. 1 film riding seal for various flow conditions. The flow model calculates the pressure drop for single and two-phase flow through the leak paths such as the labyrinth seal and the leakoff lines. The structural model determines the rotation of the seal faceplates due to thermal and pressure gradients across the seals. Results of the three models were integrated to obtain the final leakage rates.

\subsection{SEAL MODEL}

The Westinghouse RCP has three seals. The no. 1 seal is a film riding, controlled leakage seal whereas the no. 2 and 3 seals are rubbing face-type seals. The leakage across the no.1 seal cools the seal assembly. The high pressure, subcooled leakage is supplied by an injection system upstream of the no. 1 seal. Part of the injection water flows through the seal assembly. The remainder flows into the reactor coolant system as make-up water. Backup cooling is provided by a water-to-water heat exchanger parallel to the labyrinth seal. During a station blackout, both injection and cooling water would be lost. High temperature reactor coolant water would then flow into the seal system. This condition will affect the angle between the faceplates of the RCP seals and the gap between the faceplates of the no. 1 film riding. seal. The seal model calculates this gap and the pressure distribution across the no. 1 seal. The structural model, described in Section 2.3 , is used to calculate the thermal and pressure distortions.

The gap between the no. 1 seal faceplates is determined by a force balance. The inputs to the seal model include flow rate, angle between the faceplates of the seal ring and runner, enthalpy, inlet pressure, and estimate of the gap. The model calculates the pressure distribution along the seal face. This fluid pressure profile between the seal faceplates determines the opening force on the seal. The closing force on the seal is proportional to the differential pressure across the seal and acts on the upper surface of the seal ring. A schematic of these opposing forces is shown in Figure 2.

The seal model compares the calculated opening and closing forces. If these forces are unbalanced, a new gap is estimated and the procedure is repeated until the forces are balanced. The included angle between the seal faceplates is determined by the structural model based on the thermal and pressure gradients across the seal. The seal model incorporates the two-phase flow correlations used for the flow model described in Section 2.2. A more detailed description of this model is given in Appendix $A$.

\subsection{FLOW MODEL}

The reactor coolant water during normal plant operation is subcooled and is nominally 2250 psia and $550^{\circ} \mathrm{F}$. If a station blackout occurs this water will leak into the RCP seal assembly. As it flows through the RCP seal system, the pressure drop due to frictional losses causes the fluid to enter the two-phase region. Two-phase flow correlations were used to calculate pressure gradients 
FIGURE 2

\section{\#I FILM-RIDING SEAL FORCE BALANCE}

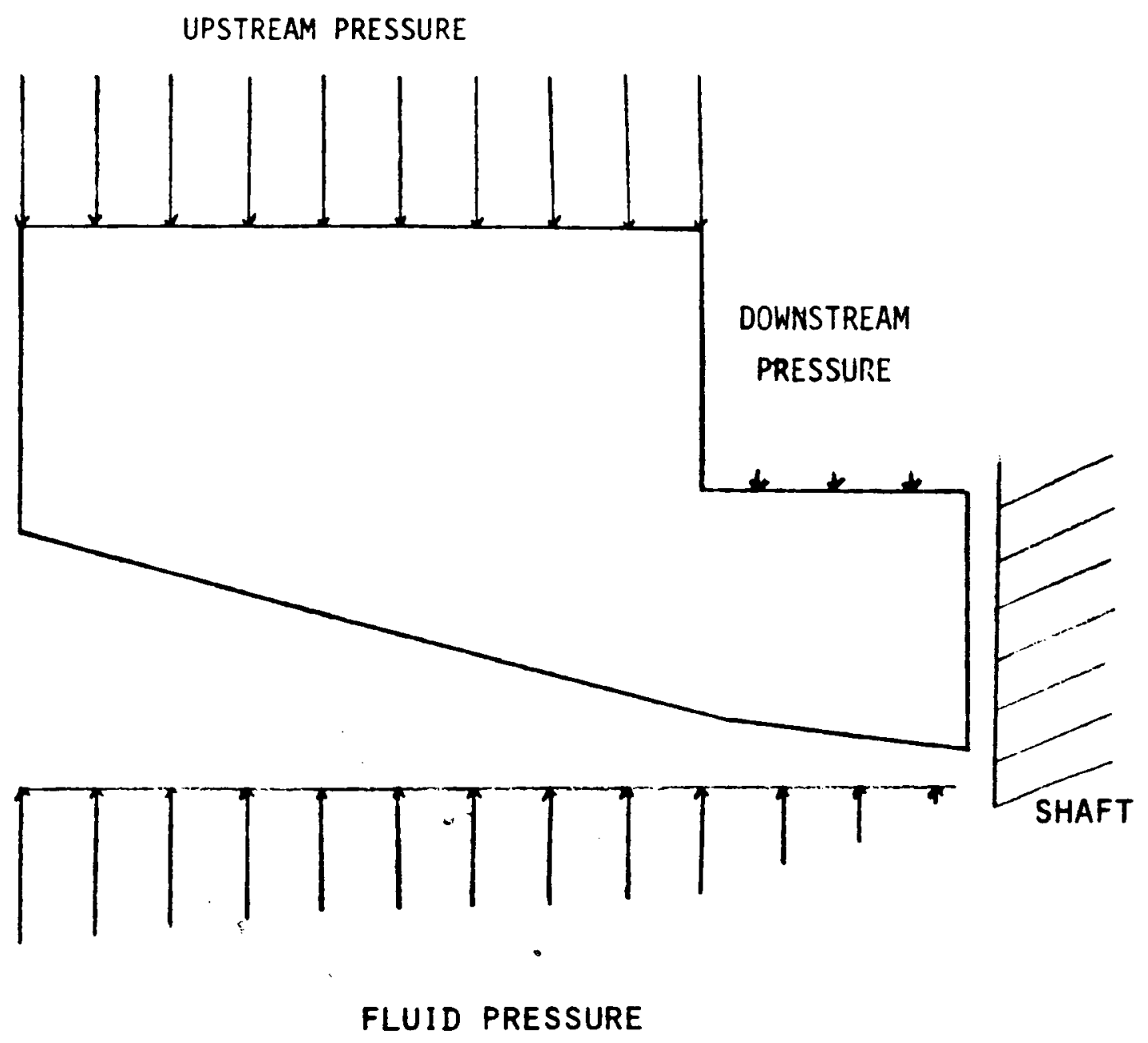


in this region. The correlations are based on the Dukler constant slip model, (ref. 2), which assumes that the ratio of the phase velocities to the average. velocity is constant across a cross section. The flow model is based on the following assumptions:

1) thermodynamic equilibrium between phases

2) adiabatic

3) one dimensional flow in the axial direction

4) steady state flow

A detailed discussion of the flow model is given in Appendix $B$.

The flow path is along the pump shaft through the labyrinth seals, through the cartridge seal internals, and either through one of the three seal leakoff lines or out the top of the pump casing (see Figure 1). If the no. 1 seal is functional, the fluid enters the two-phase region as it passes through the seal. If the no. 1 seal is not functional, two-phase flow may begin in the labyrinth or in the no. 1 leakoff line. Although proprietary dimensional data excluded from this report was provided by Westinghouse so that an accurate analys is could be conducted.

The inputs to the flow model are reservoir pressure and enthalpy, flow path dimensions, and estimated flow rate. The flow rate estimate is modified until the downstream pressure condition is reached or until choked flow occurs. The downstream pressure condition for the no. 1 leakoff line was 165 psia. This is the set pressure specified by Westinghouse as typical for the no. 1 seal leakoff line pressure relief valve. For the other leakoff lines and for flow out of the top of the pump casing, ambient pressure, approximately 15 psia, was the downstream pressure boundary condition.

\subsection{STRUCTURAL MODEL}

The deformations of the three seal assemblies were analyzed using the ANSYS program, reference 3. The ANSYS computer program is a general purpose, finite element computer program for the solution of linear and nonlinear structural problems. The matrix displacement method of analys is based upon finite element idealization is used. The ANSYS program was used to model the three dimensional seal assemblies. Pressure and temperature loading were applied to the seal models. 


\subsection{RESULTS}

The RCP seal analysis addressed the following:

1) the effect seal failure has on RCP leakage

2) the effect of system cooldown and depressurization on leakage rates and

3) the sensitivity of leakage rates to dimensional and thermal hydraulic parameters.

For each of the three cases, it is assumed that pump rotation stops immediately after station blackout occurs. A discussion of the results for (1) all three seals function, (2) no. 1 seal fails open while the no. 2 and 3 seals function, and (3) all three seals fail is presented in Sections 3.1 through 3.3, respectively. Figure 3 graphically summarizes the results for reactor coolant system (RCS) conditions of 2250 psia and $550^{\circ} \mathrm{F}$. Section 3.4 presents a brief, general discussion of results pertaining to 0 -ring and channel seals. Section 3.5 discusses uncertainty associated with the entire analysis.

\subsection{ALL THREE SEALS FUNCTION}

The RCS pressure and temperature are nominally 2250 psia and $550^{\circ} \mathrm{F}$ during power plant operation. If loss of ac power and station blackout occur, RCS water at these conditions would leak into the RCP seal assembly. The temperature change would cause a change in leakage rate. ETEC calculated a leakage rate of $19.6 \mathrm{gpm}$ with RCS pressure equal to $2250 \mathrm{psia}$ and a RCS temperature of $550^{\circ} \mathrm{F}$ assuming all three seals function. This predicted leakage rate is slightly less than the $21.1 \mathrm{gpm}$ leak rate predicted by Westinghouse for the same conditions. The nominal leak rate for the RCP seal assembly during normal plant operation when injection water is available, is 3 gpm.

\subsubsection{Initial RCS Conditions}

As previously indicated, the initial RCS conditions following a station blackout are $2250 \mathrm{psia}$ and $550^{\circ} \mathrm{F}$. In order to calculate a leakage rate through the RCP seal assembly at these conditions, the three models described in Section 2 were used. The flow model was used to calculate the pressure drop due to single and two-phase flow through all flow paths excluding the flow through the seals themselves. The seal model was used to calculate the pressure distribution across the seal faceplate and the gap between the faceplates. The structural model was used to determine the included angle between the faceplates due to deformation caused by the temperature and pressure differentials across the seal.

The ANSYS model was run to determine the response of the no. 1 seal to temperature and pressure loadings. The model independently determines response to the pressure and temperature loadings. Curves of seal rotation versus differential pressure and temperature were generated, and are illustrated in Figures 4 and 5 . The curves represent linear interpolation of response for pressure or temperature differentials. 
FIGURE 3

COMPARATIVE LEAKAGE RATES

2250 PSIA $6550 \mathrm{~F}$

LEAKMEE (EDI)

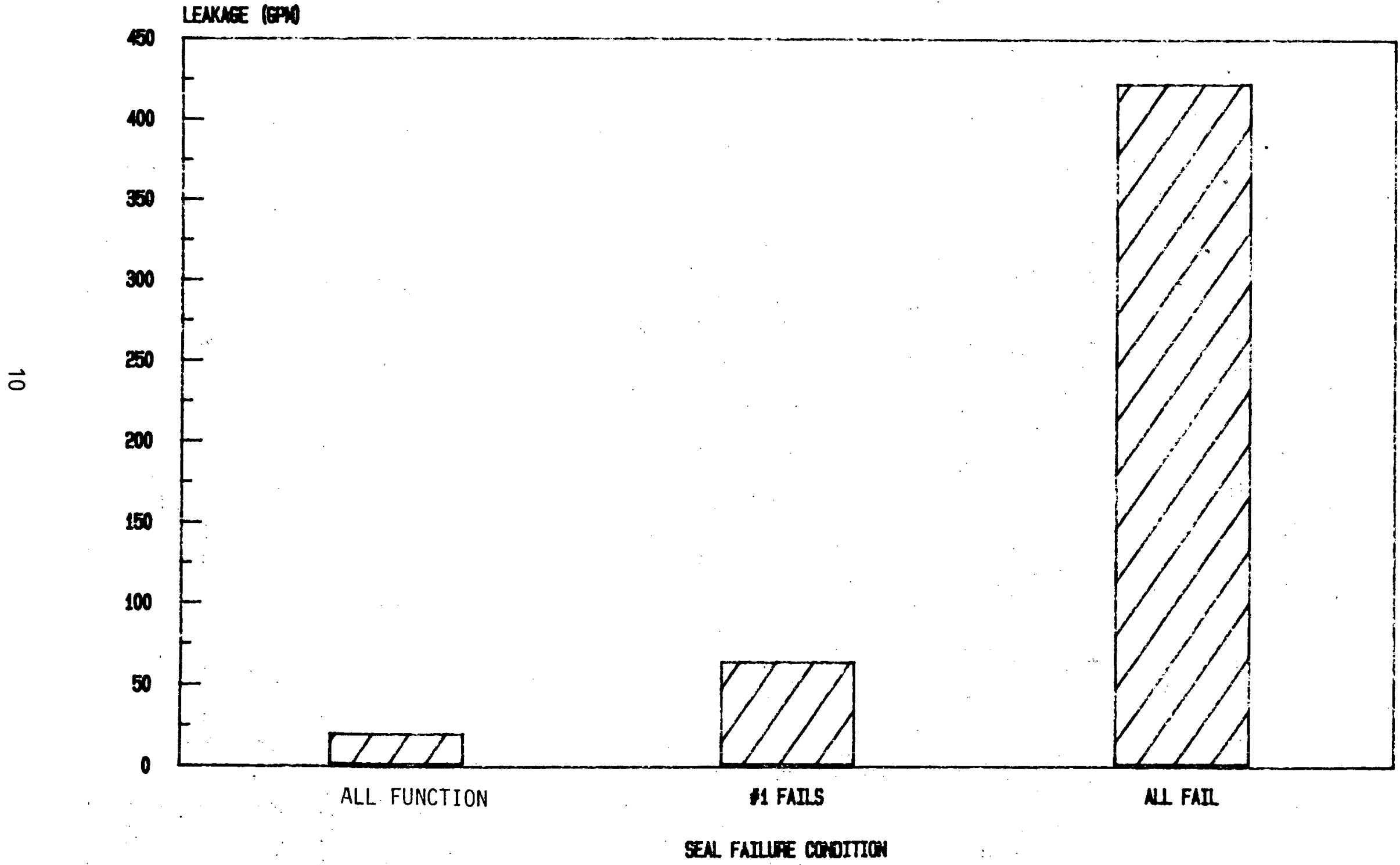




\section{FIGURE 4:}

\section{DECREASE \#1 SEAL ANGLE VS DELTA PRESSURE}

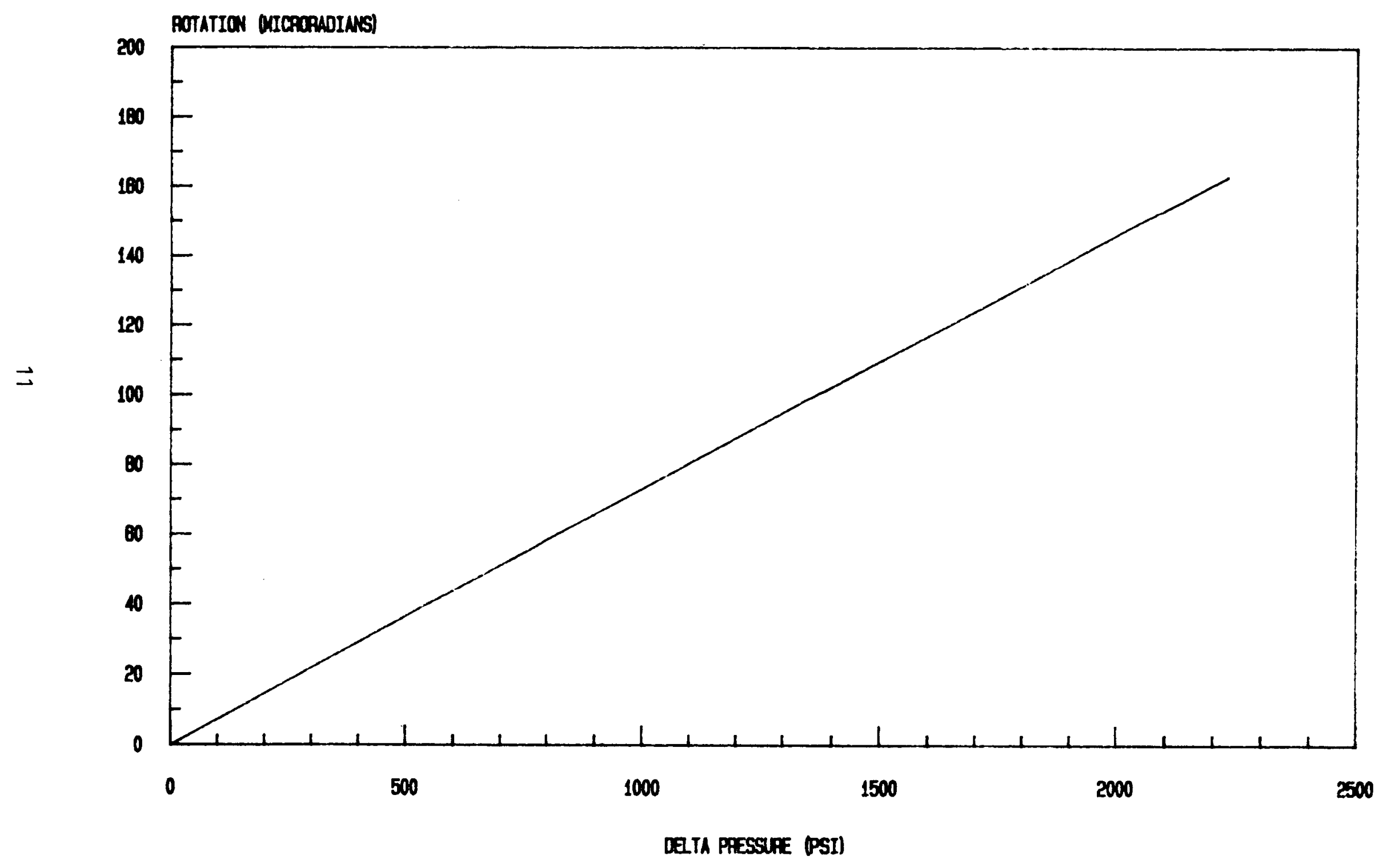


FIGURE 5:

INCREASE IN \#1 SEAL ANGLE VS DELTA TEMP.

hotation Mitchophoians)

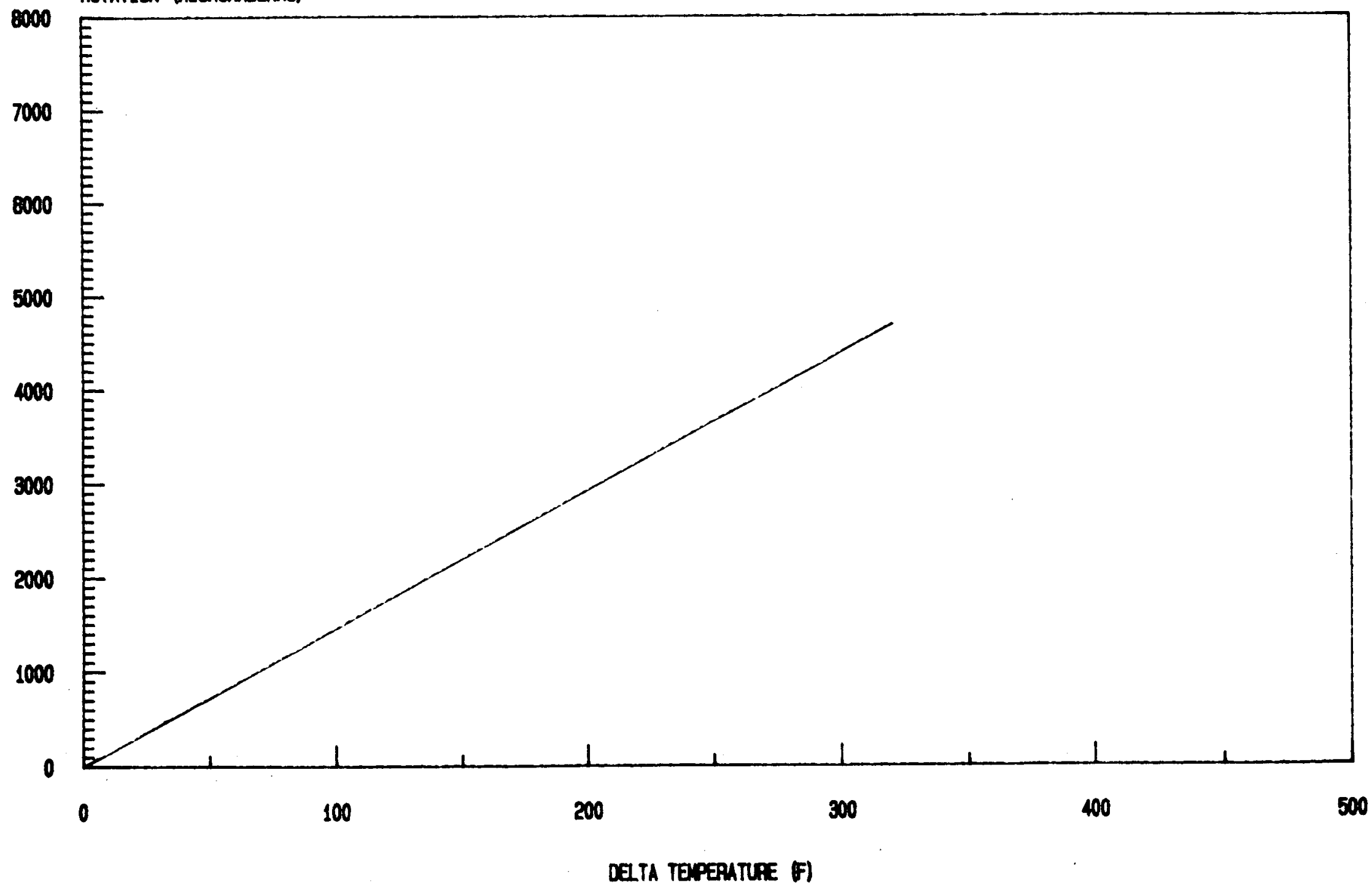


The temperature and pressure differentials used in the ANSYS structural model were used for developement of Figures 4 and 5 . The selection of the temperature differential and pressure distribution used as inputs for the model was arbitary. For the thermal analysis of the no. 1 seal, ETEC assumed $550^{\circ} \mathrm{F}$ upstream of the seal and $518^{\circ} \mathrm{F}$ downstream. These conditions were chosen because they are the conditions predicted by Westinghouse for the no. 1 seal when all three seals function during a station blackout. Figure 6 is an isotherm plot of the no. 1 seal subjected to this thermal gradient. As discussed later, ETEC predicted different temperature conditions for the no. 1 seal. However, by selecting the Westinghouse conditions for ANSYS model inputs, ETEC was able to compare results of seal rotation versus thermal gradient across the no. 1 seal. The ETEC results are shown in Figure 5 and are similar to those presented by Westinghouse in reference 1 . Note that the included angle increases as the temperature gradient increases.

The nominal pressure conditions during normal pump operation, 2250 psia upstream and 30 psia downstream, were used for analys is of the no. 1 seal rotation due to differential pressure. The pressure gradient along the seal faceplates was obtained from the seal model described in Section 2.1. These boundary conditions were chosen because the pressure gradient across the no. 1 seal during normal operation, that is with a.c. power and cooling water available, is greater than the pressure gradient across the no. 1 seal during station blackout. The seal rotation due to pressure gradients across the faceplates therefore is bounded by the rotation caused by the normal 2220 psia pressure differential and a zero pressure gradient. Figure 4 illustrates the dependency of seal rotation on differential pressure for the no. 1 seal. This graph shows that increases in the differential pressure cause the seal to rotate closed. This is in contrast to the reaction of the no. 1 seal to increases in the temperature gradient. Therefore, the seal opening rotation due to the temperature gradient and the closing rotation caused by the differential pressure tend to offset each other.

Figures 4 and 5 were used to determine angular rotation of the seal faceplates. An iterative process was used to reconcile the results of the flow and seal models with the structural model. The first step was to assume an included angle between the no. 1 seal faceplates for input into the seal model. The seal model predicted a pressure differential and a resultant temperature drop based upon this included angle. A new included angle was then generated based on the upstream and downstream pressures and temperatures predicted by the flow and seal models. Using this method, conditions for the no. 1 seal functioning during station blackout are $2247 \mathrm{psia}$ and $550^{\circ} \mathrm{F}$ upstream and $935 \mathrm{psia}$ and $535^{\circ} \mathrm{F}$ downstream.

The no. 2 and 3 rubbing face type seals rotate closed under normal power plant operating conditions when injection water is available to cool the seal assembly. During station blackout the no. 2 and 3 seals are subjected to higher temperatures which increase the gradient across the seals.

ETEC analyzed the no. 2 seal assuming $518^{\circ} \mathrm{F}$ upstream and $212^{\circ} \mathrm{F}$ downstream to determine if an increase in the temperature gradient would make the seal 
FIGURE 6 :

ISOTHERM MAP OF \#I SEAL

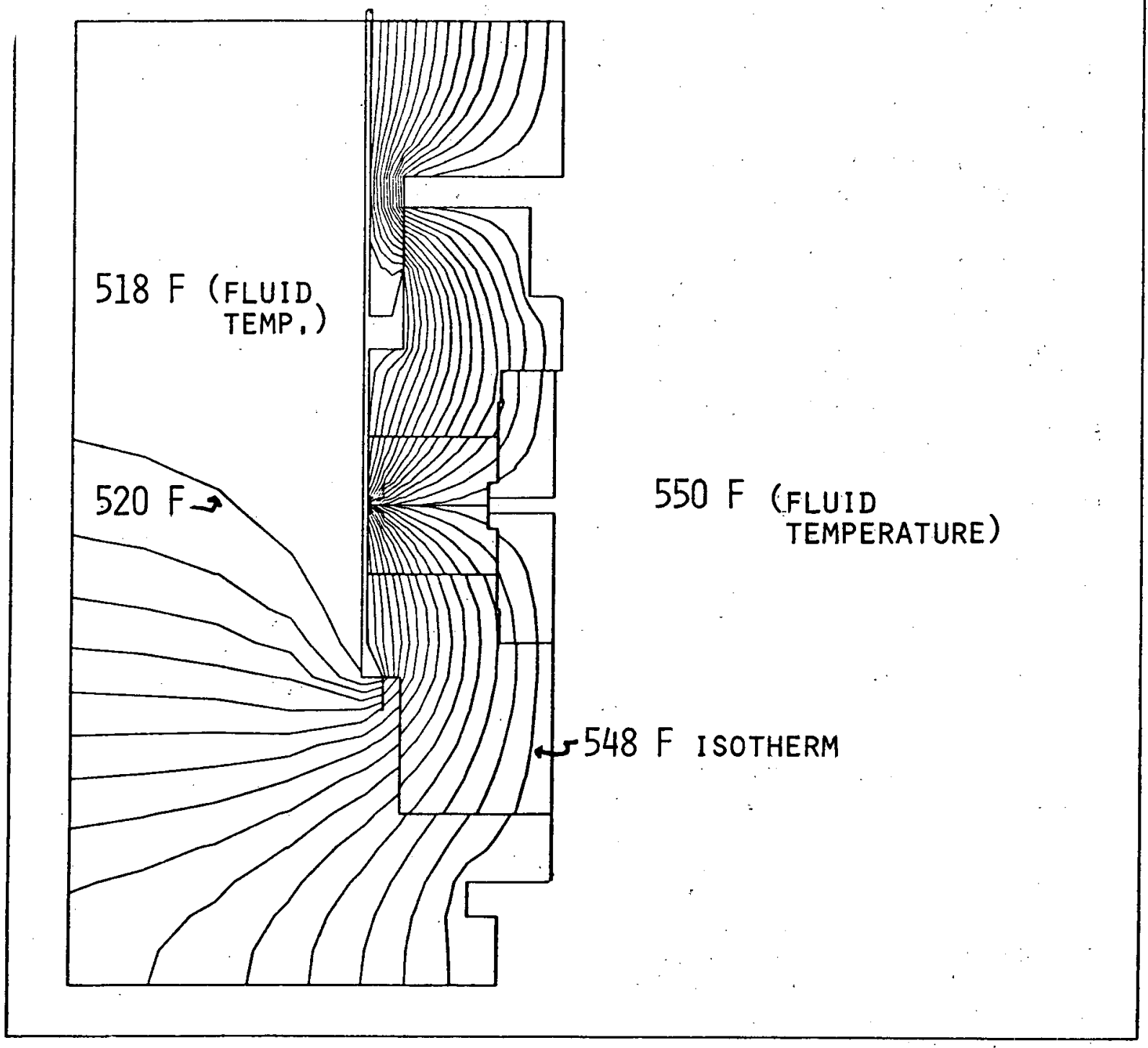


rotate closed. The temperatures used for the analys is were selected to identify whether an increase in temperature gradient caused the normally closed seal to rotate open or remain closed. If an increase in the temperature differential caused the seal to rotate open, it would be necessary to evaluate the flow through the no. 2 seal at each upstream condition. However, if an increase in temperature gradient produced a closing rotation of the seal, then only a minimal amount of flow will leak through regardless of the upstream conditions.

The isotherm plot from the thermal analysis of the no. 2 seal is shown in Figure 7. ETEC's analysis verified the Westinghouse prediction that the no. 2 seal's closing rotation would increase with differential temperature. Thus, the no. 2 seal will rotate closed whenever the temperature gradient exceeds the gradient experienced by the seal under normal operating conditions. This includes all the conditions predicted during a station blackout.

The actual conditions upstream of the no. 2 seal are determined by the reactor coolant system temperature and pressure and by the pressure drop across the labyrinth seal and the no. 1 seal. The ETEC analysis predicts that the temperature upstream of the no. 2 seal will be $535^{\circ} \mathrm{F}$ when the no. 1 seal is functioning. The temperature downstream of the no. 2 seal should be $212^{\circ} \mathrm{F}$, the saturation temperature of water at ambient pressure. Westinghouse predicted $518^{\circ} \mathrm{F}$ upstream and $212^{\circ} \mathrm{F}$ downstream of the no. 2 seal. Therefore, the ETEC analysis indicates a larger temperature gradient across the no. 2 seal and therefore larger closing rotation.

\subsubsection{RCS Cooldown and Depressurization}

The leakage rate of $19.6 \mathrm{gpm}$ reported for the case when all three seals function during a station blackout was based on the initial RCS conditions of $2250 \mathrm{psia}$ and $550^{\circ} \mathrm{F}$. However, the reactor coolant system pressure and temperature will decrease during the station blackout due to decreasing volume and possibly due to operator action. If the operators initiate cooldown procedures, Westinghouse predicts the reactor coolant system pressure and temperature will respond as shown in Figures 8 and 9 (ref. 1). The leakage rate with all three seals functioning was calculated at a number of these conditions. The results are tabulated in Table 1. These data were used to estimate the accumulated leakage versus time as shown in Figure 10.

If the operators do not initiate system cooldown procedures, the reactor coolant system pressure will still decay during the station blackout although Westinghouse predicts that the temperature will be fairly constant. These system conditions are presented in Figures 11 and 12. The calculated leakage rates are given in Table 2. For comparison, the accumulated leakage versus time corresponding to the no cooldown case is presented in Figure 10 alongside the curves of accumulated leakage for the cooldown case. The graph emphasizes the impact that operator action can have on the accumulated leakage and thus the time required to expose the core. The leakage rates for the cooldown and the no cooldown case would be the same for identical RCS conditions. The large difference in accumulated leakage is because the RCS remains at high temperature and pressure conditions which result in higher leakage rates. 
FIGURE 7:

ISOTHERM MAP OF THE \#2 SEAL

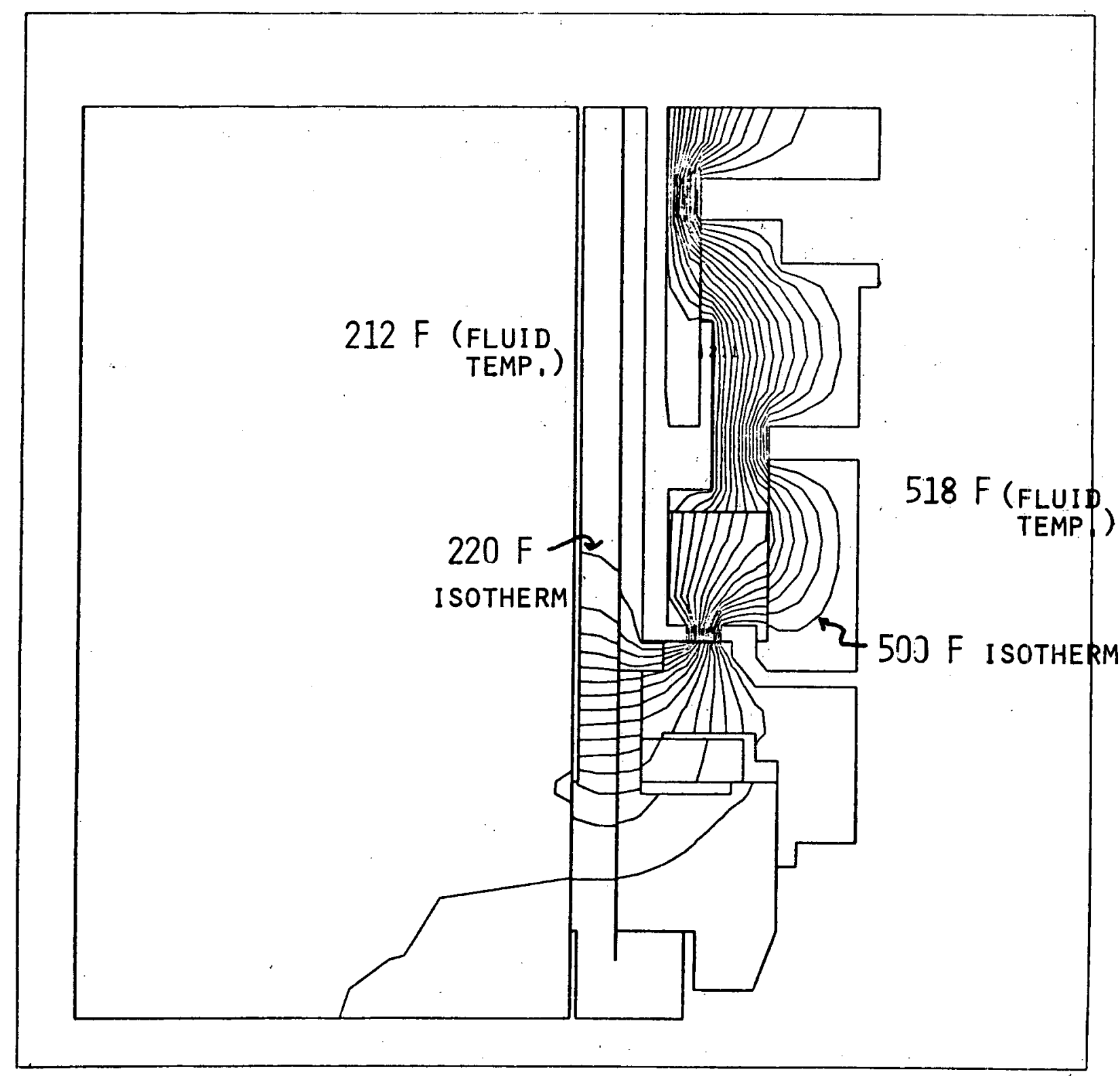


FIGURE 8:

REACTOR COOLANT SYSTEM PRESSURE VS. TIME

OPEPATOA INITIAJED COOLOOAN

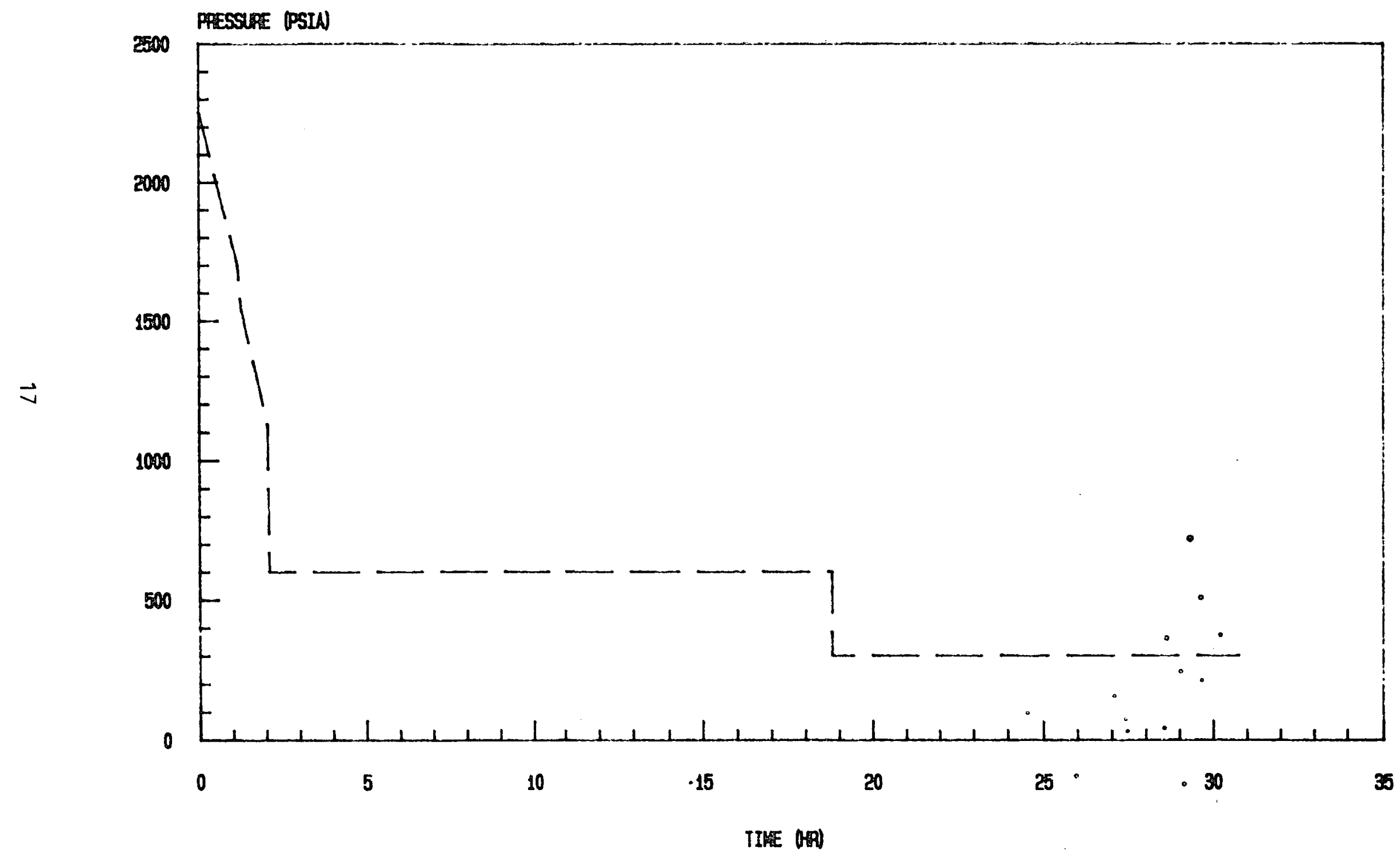


FIGURE 9:

RCS TEMPERATURE VS. TIME

OPERATOA INITIATED CONDONN

TEPERTIRE FI

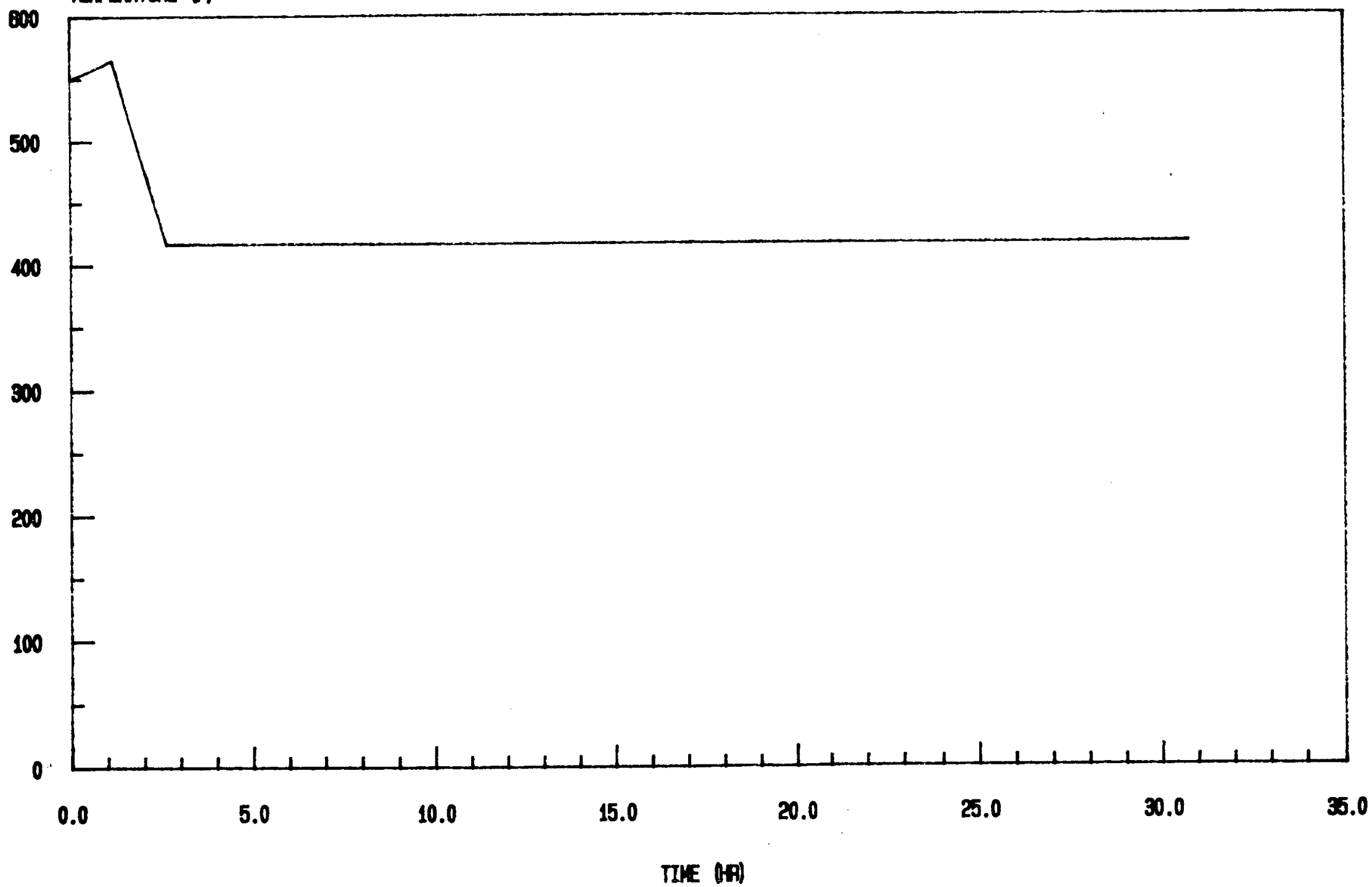


TABLE 1: LEAKAGE RATES DURING REACTOR COOLANT COOLDOWN ALL SEALS FUNCTION

\begin{tabular}{|c|c|c|c|}
\hline \multicolumn{2}{|c|}{$\begin{array}{c}\text { Reactor Coolant System } \\
\text { Pressure (psia) } \\
\left.{ }^{\circ} \mathrm{F}\right)\end{array}$} & \multicolumn{2}{|c|}{ Leakage Rate } \\
\hline 2250 & 550 & 2.05 & 19.6 \\
\hline 600 & 444 & .92 & 8.0 \\
\hline 300 & 417 & .46 & 3.9 \\
\hline
\end{tabular}

*Based on Reactor Coolant System density 
FIGURE 10:

ACCUMULATED LEAKAGE VS. TIME

ALL SEALS FUNCTION

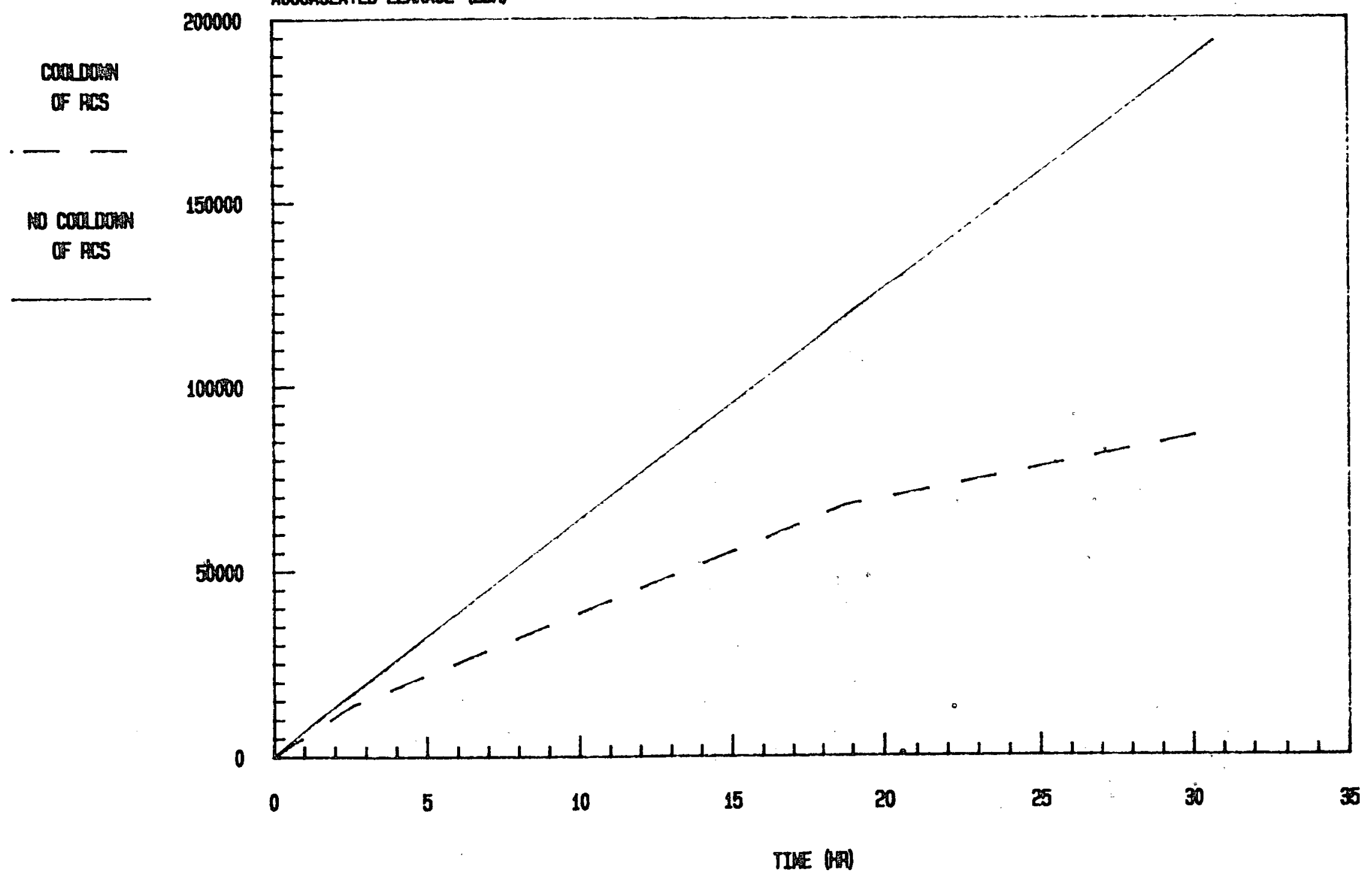


FIGURE 11:

REACTOR COOLANT SYSTEM PRESSURE VS. TIME no coondow

PressuF PSIN

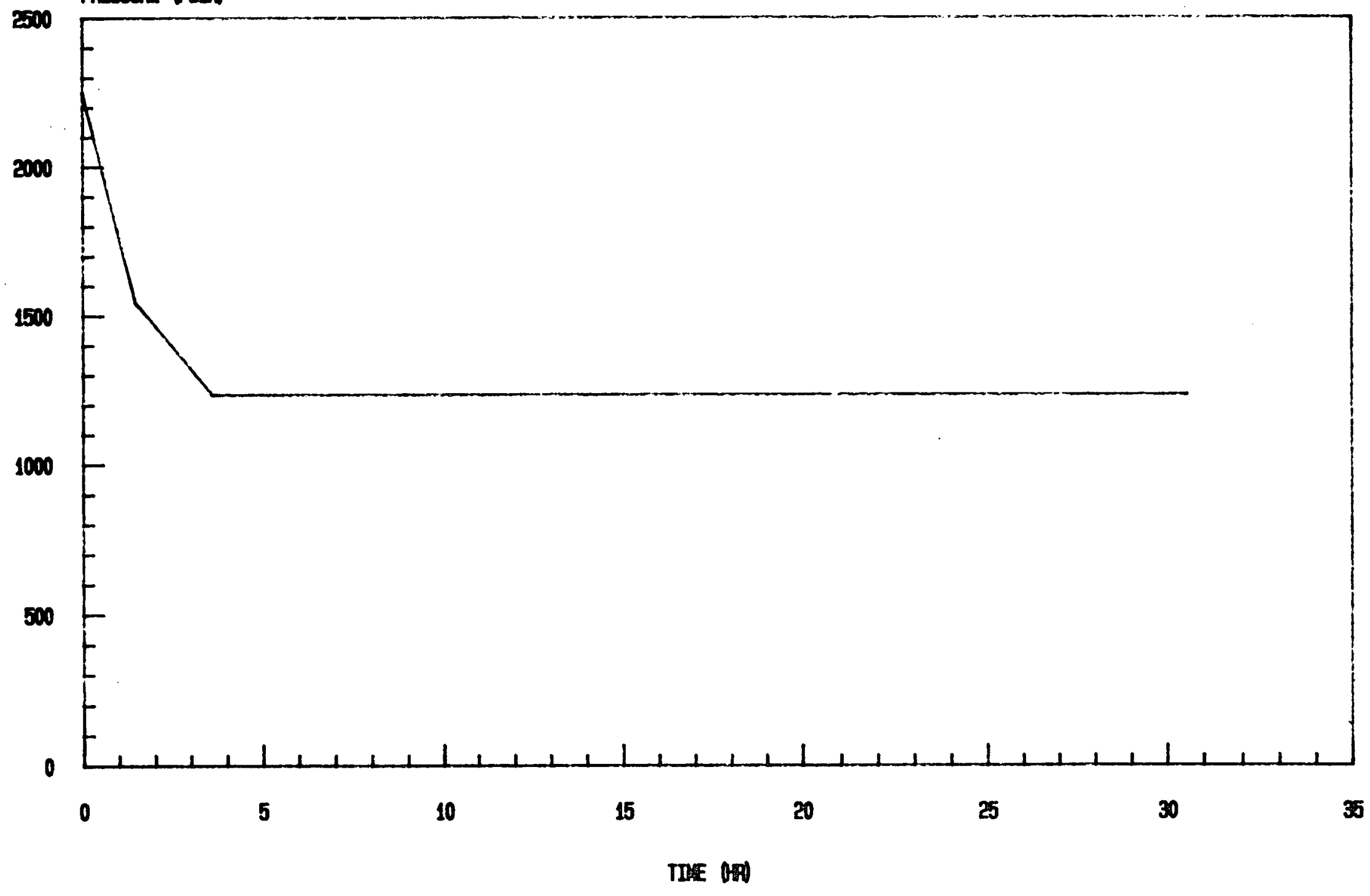


FIGURE 12 :

RCS TEMPERATURE VS. TIME

in coondowis

TEPERTHE OF

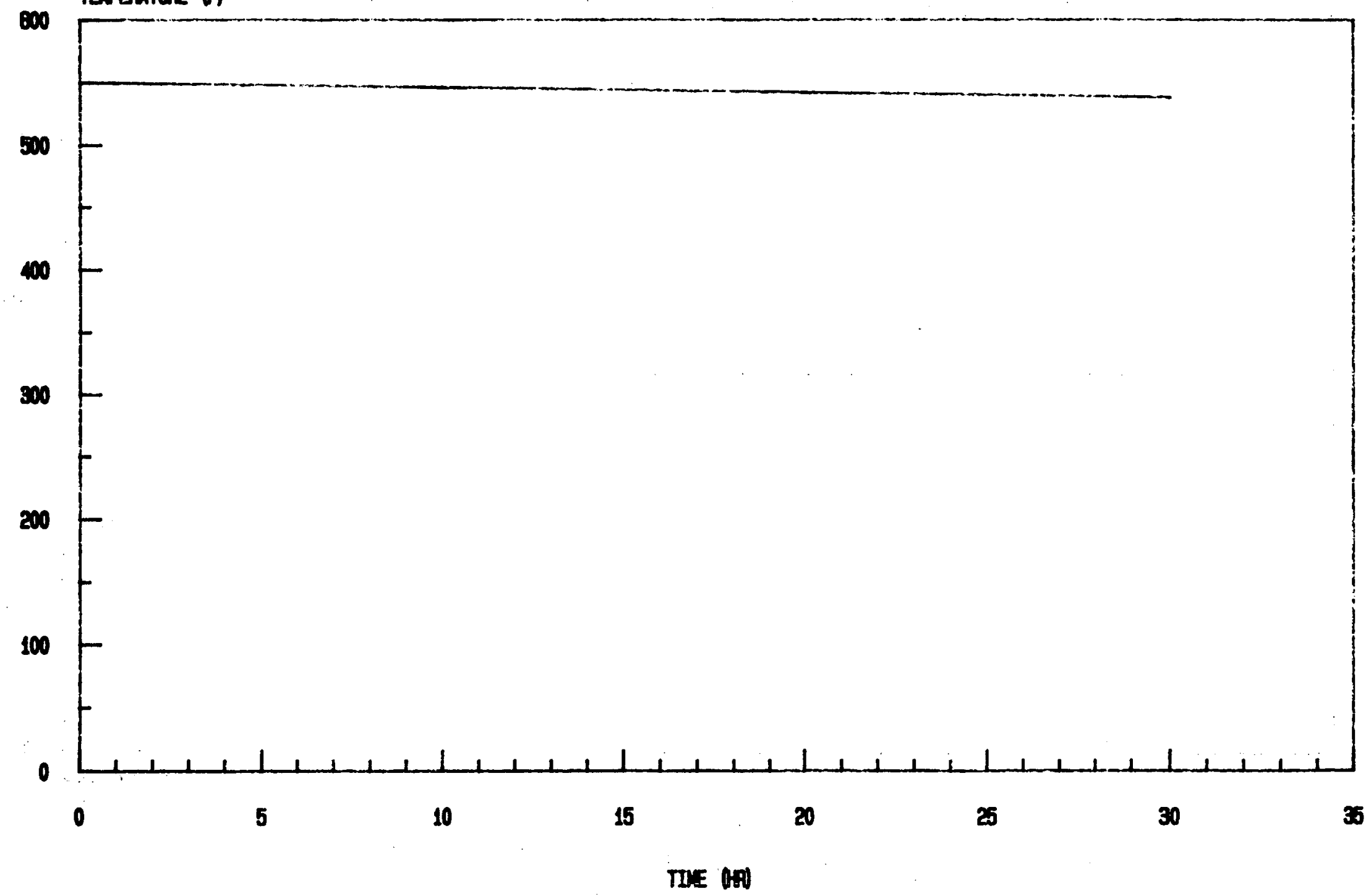


TABLE 2: LEAKAGE RATES WITHOUT REACTOR COOLANT SYSTEM COOLDOWN ALL SEALS FUNCTION

\begin{tabular}{cccc}
\hline \multicolumn{2}{c}{ Reactor Coolant System } & \multicolumn{2}{c}{ Leakage Rate } \\
Pressure (psia) & Temperature $\left({ }^{\circ} \mathrm{F}\right)$ & lbm/sec & gpm * \\
\hline 2250 & 550 & 2.05 & 19.6 \\
1545 & 549.3 & 1.75 & 16.9 \\
1235 & 548.6 & 1.74 & 16.9 \\
\hline
\end{tabular}

*Based on Reactor Coolant System density 


\subsubsection{Sensitivity Studies}

The ANSYS structural model was used to determine the influence of several thermal parameters on seal faceplate included angle and the calculated leakage rate. The first parameter investigated was the heat transfer coefficient used at the fluid/seal interface. ETEC initially used a heat transfer coefficient of $14 \mathrm{Btu} /\left(\mathrm{hr} \mathrm{in}^{\star} \mathrm{in} \star \mathrm{F}\right)$, a value in the typical range for water/metal theat transfer. Through discussions with Westinghouse and examination of the isotherms Westinghouse presented for the no. 1 and no. 2 seals, see reference 1, it became evident that Westinghouse had used a higher heat transfer coefficient. ETEC therefore repeated the ANSYS analysis using a heat transfer coefficient of $1000 \mathrm{Btu} /\left(\mathrm{hr}^{\star} i \mathrm{n}^{*} i \mathrm{n}^{\star} \mathrm{F}\right)$. Use of this very high heat transfer coefficient resulted in approximately equal fluid and metal temperatures. The temperature drop across the seal was larger when the higher heat transfer coefficient was assumed. The larger temperature drop produced a larger included angle between the seal faceplates, causing a larger leak rate. ETEC used the high heat transfer coefficient, $1000 \mathrm{Btu} /\left(\mathrm{hr} \star \mathrm{in}^{*} \mathrm{in} * \mathrm{~F}\right)$, because it produced more conservative results.

The assumption of isothermal seal faceplates was compared to the assumption of no heat transfer across the faceplate, see Figures 13 and 14 . The no heat transfer assumption means the temperature of the faceplates is the same as the temperature of the fluid in contact with the faceplates. The assumption of isothermal seal faceplates means that the entire surface of the seal faceplate is at the same temperature, the temperature of the incoming fluid. The isothermal faceplate assumption gives a greater opening rotation of the seal faceplates, which allows a greater leak rate through the seal. ETEC determined that the assumption of isothermal faceplates was reasonable during their study. The seal model, see section 2.1, predicted that flashing of the leakage water will not occur until the fluid reaches the downstream edge of the no. 1 seal. Before the fluid flashes, it is subcooled and so the temperature remains constant as the pressure decreases. Therefore, even if the no heat transfer assumption was made, the no. 1 seal faceplates would still be virtually isothermal. ETEC assumed the faceplates would be isothermal because this assumption appears to approximate the true situation but is somewhat more conservative. Westinghouse also assumed the faceplates are isothermal.

The effect of machining tolerance on the leakage rate through a functioning no. 1 seal was examined. The rolling stiffness of the support ring with the faceplate is predicted to change approximately $1.1 \%$ from a seal with the nominal machined dimensions. The rolling stiffness influences the rotation of the no. 1 seal. The effect of dimensional tolerances on the axial force balance was also calculated. The axial force balance determines the gap between the seal faceplates. The allowable dimensional deviation is predicted to change the axial force by only $0.73 \%$ from the nominal case. Machining tolerances therefore would have only a minor impact on the calculated leakage rates.

\subsection{NO. 1 SEAL FAILURE}

For the case assuming that the no. 1 seal fails open while the no. 2 and 3 seals continue to function, ETEC predicted a leak rate of $64.7 \mathrm{gpm}$ through the 
FIGURE 13

ISOTHERM MAP OF \#I SEAL

I SOTHERMAL FACEPLATES

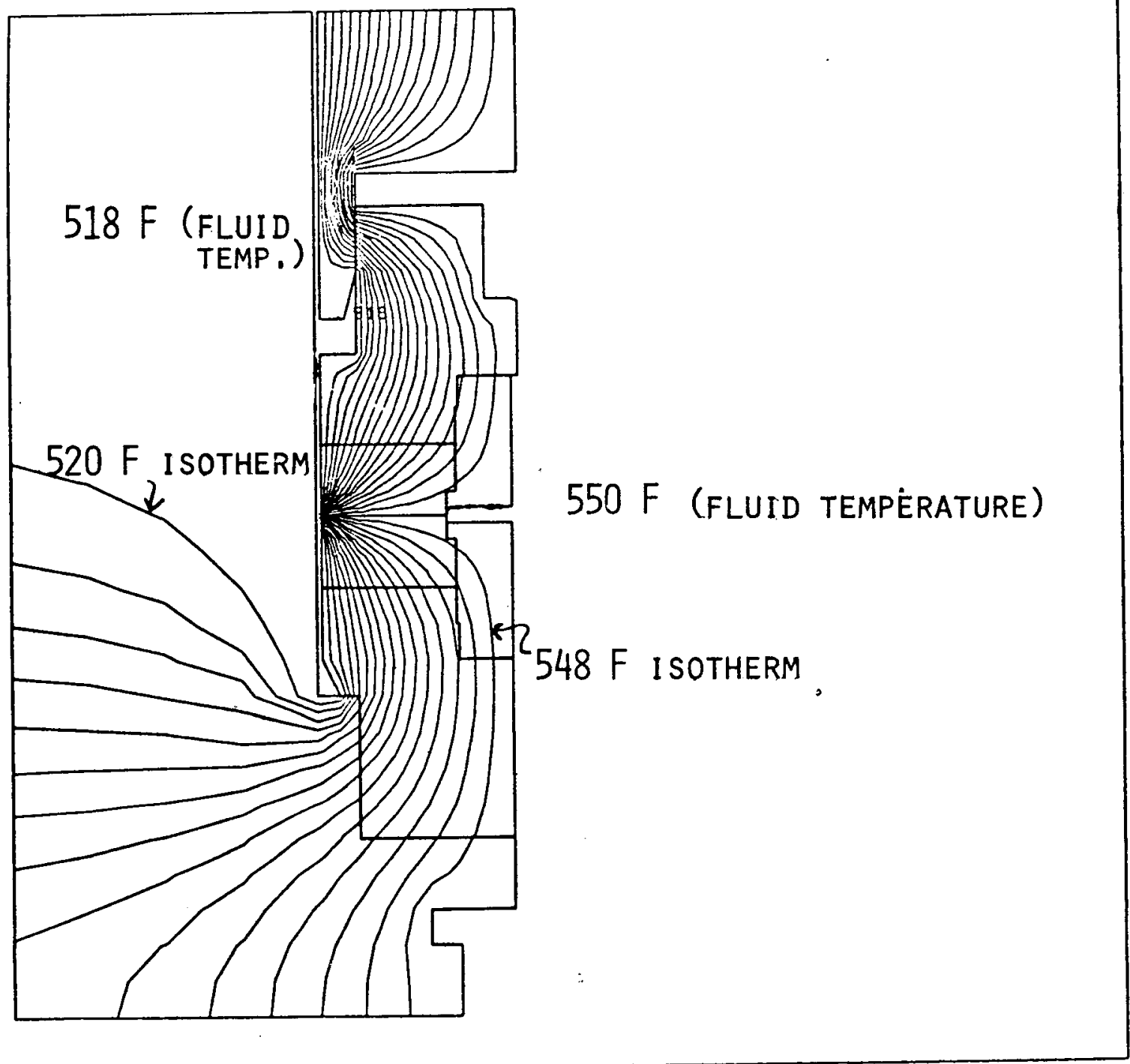


FIGURE 14

ISOTHERMAL MAP OF \#1 SEAL

NO HEAT TRANSFER ACROSS FACEPLATES

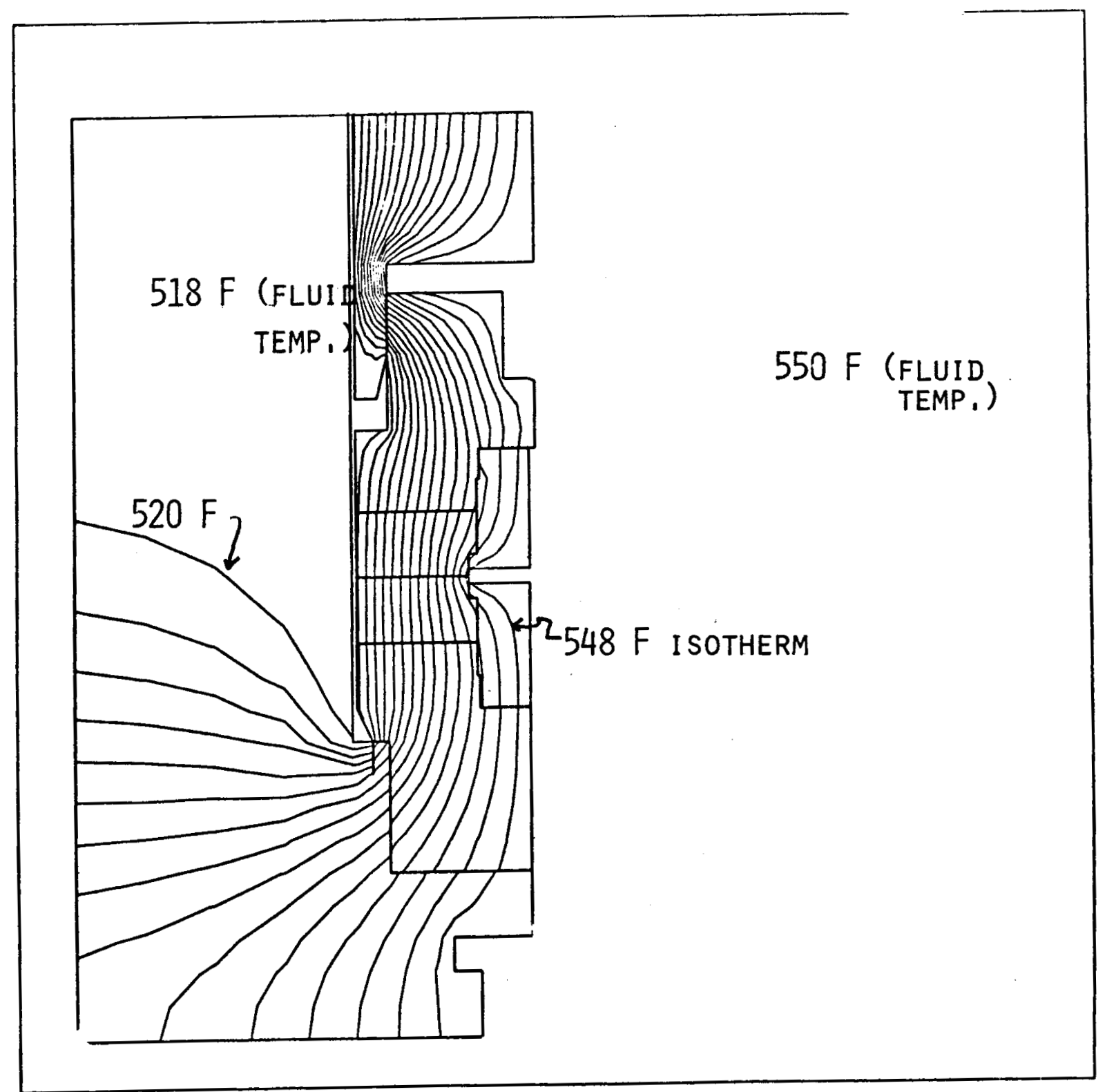


RCP seal assembly with RCS at 2250 psia and $550^{\circ} \mathrm{F}$. This is comparable to the $75.6 \mathrm{gpm}$ leak rate predicted by Westinghouse for the same conditions.

\subsubsection{Initial RCS Conditions}

The initial RCS conditions during a station blackout were assumed to be 2250 psia and $550^{\circ} \mathrm{F}$. These are the nominal RCS conditions during normal power plant operation. It also was assumed that failure of the no. 1 seal occurred immediately upon station blackout and that pump rotation has stopped. This is a conservative assumption which gives the maximum leak rate.

Two of the models described in section 2 were used, for this analysis. The seal model, which defines the gap and pressure distribution across the no. 1 film-riding seal, was not required. The structural model was used to determine the response of the no. 2 and 3 rubbing face seals. As for the case when all three seals function, the temperature gradient across the no. 2 seal causes it to rotate closed. The conditions upstream of the no. 2 seal are approximately $2220 \mathrm{psia}$ and $550^{\circ} \mathrm{F}$. Downstream of the no. 2 seal, the fluid wi 11 be at saturation; $15 \mathrm{psia}$ and $212^{\circ} \mathrm{F}$. The temperature gradient across the no. 2 seal will be greater than if the no. 1 seal functions so the closing rotation will be larger.

The primary leak path is through the no. 1 seal and the no. 1 leakoff line with only minimal flow through the no. 2 seal. If the no. 2 seal faceplates are machined perfectly flat, there would be no leakage across a closed no. 2 seal. In practice, there will be some leakage due to machining tolerances. The leakage past the no. 2 seal when it rotates closed was therefore estimated. Based on the maximum permitted circumferential 'wave' for the no. 2 seal runner face, a leakage rate of approximately $0.1 \mathrm{gpm}$ was calculated. Upstream conditions of $2250 \mathrm{psia}, 550^{\circ} \mathrm{F}$ and downstream conditions of $15 \mathrm{psia}$, $212^{\circ} \mathrm{F}$ were chosen for the analysis to give the maximum leakage rate. This leakage of $0.1 \mathrm{gpm}$ is insignificant compared with the overall leakage rates. Since the no. 3 seal is downstream of the no. 2 seal, leakage across the no. 3 seal is limited by no. 2 seal leakage.

\subsubsection{RCS Cooldown and Depressurization}

As discussed in section 3.1.2 for the case in which all three seals function, the leak rate through the RCP seal assembly will decrease due to system cooldown and depressurization. If the operators initiate cooldown procedures, Westinghouse predicts the RCS temperature and pressure profiles versus time will be as shown in Figures 8 and 9 . These temperature and pressure responses are dependent on the volumetric capacity of the equipment and on the time it takes to drain the various portions of the system. The time it takes to drain depends on the leakage rate at different RCS pressures and temperatures. The RCS conditions versus time presented in Figures 8 and 9 are based on a fourloop plant and the leak rates Westinghouse predicted, assuming that all three seals function throughout the station blackout. ETEC used these same conditions in the analysis of accumulated leakage versus time for the case in which the no. 1 seal fails open while the no. 2 and 3 seals function. Since the leakage rates are higher when the no. 1 seal fails, some error is introduced with this method. In fact, the depressurization of the system would occur more quickly if the no. I seal failed because the system would be draining faster. This indicates that the accumulated leakage versus time 
calculated by ETEC for the case with the no. 1 seal failed and the no. 2 and 3 seals functioning is conservative. That is it gives greater accumulated leakage.

The leakage rates calculated by ETEC for various RCS conditions following operator initiated cooldown are summarized in Table 3. These data were used to estimate the accumulated leakage versus time as shown in Figure 10 . As discussed above, these results should be conservative.

If the operators do not initiate system cooldown procedures, Westinghouse predicts the RCS will respond as shown in Figures 11 and 12 . These pressure and temperature time histories are also based on the leakage rates calculated when all three seals function. Therefore, the error discussed above extends to ETEC's calculation of accumulated leakage versus time without operator initiated cooldown for the case in which the no. 1 seal fails while the nos. 2 and 3 function. The leakage rates at various RCS conditions are given in Table 4. The accumulated leakage versus without operator initiated cooldown is presented in Figure 15 with accumulated leakage for operator cooldown.

\subsubsection{Sensitivity Studies}

The dominant flow resistance when the no. 1 seal fails open and the no. 2 and 3 seals function is the no. 1 seal leakoff line. ETEC calculated a pressure drop of approximately 2035 psia across this leakoff line. These lines vary from plant to plant. ETEC used a 'typical' configuration provided by Westinghouse. An isometric of this line is shown as Figure 16. Since there is variation in these lines among plants, ETEC evaluated the response of the leakage rate to changes in the line configuration.

Two alternative configurations illustrated in Figures 17 and 18 were examined. The response of the leakage rate to modification of the leakoff line configuration is illustrated in Figure 19. The results indicate that the leakoff line arrangement, as well as the overall equivalent flow resistance $(L / D)$ affects the leakage rate. The leakoff configuration shown in Figure 17 differs from that shown in Figure 16 only by elimination of the last section of 2" diameter pipe. This modification has no effect on the leakage rate. However, if the section of $11 / 4$ " diameter piping located upstream of this 2" piping is removed, as shown in Figure 18, the leakage rate increases by $13 \%$. This is because flow chokes in the final section of $11 / 4$ " pipe, and thus the relatively large pipe downstream does not limit the leakage rate.

\subsection{ALL SEALS FAIL}

The worst case leakage rate through the RCP seal assembly during a station blackout would occur if all three of the seals fail. For this case ETEC predicted a leakage rate of $422 \mathrm{gpm}$ with RCS conditions of $2250 \mathrm{psia}, 550^{\circ} \mathrm{F}$. Westinghouse predicted a $480 \mathrm{gpm}$ leakage rate under the same conditions.

\subsubsection{Initial RCS Conditions}

It was assumed that seal failure occurred immediately after loss of ac power and therefore the RCS conditions should be approximately the same as normal plant operation. The assumption of immediate failure gives the largest leakage rate. 
TABLE 3: LEAKAGE RATES DURING REACTOR COOLANT SYSTEM COOLDOWN \#1 SEAL FAILS, \#2 \& \#3 FUNCTION

\begin{tabular}{cccc}
\hline \multicolumn{2}{c}{ Reactor Coolant System } & \multicolumn{2}{c}{ Leakage Rate } \\
Pressure (psia) & Temperature $\left({ }^{\circ} \mathrm{F}\right)$ & lbm/sec & gpm $^{*}$ \\
\hline 2250 & 550 & 6.76 & 64.7 \\
1700 & 565 & 4.82 & 47.6 \\
1540 & 555 & 4.53 & 44.2 \\
1124 & 474 & 4.84 & 43.0 \\
600 & 471 & 2.26 & 20.1 \\
600 & 417 & 3.50 & 29.6 \\
300 & 417 & .95 & 8.1 \\
\hline
\end{tabular}

* Based on Reactor Coolant System Density 
TABLE 4: LEAKAGE RATES WITHOUT REACTOR COOLANT: SYSTEM COOLDOWN \#1 SEAL FAILS, \#2 \& \#3 SEALS FUNCTION

\begin{tabular}{cccc}
\hline \multicolumn{2}{c}{ Reactor Coolant System } & \multicolumn{2}{c}{ Leakage Rate } \\
Pressure (psia) & Temperature $\left({ }^{\circ} \mathrm{F}\right)$ & 1bm/sec & gpm* \\
\hline 2250 & 550 & 6.76 & 64.7 \\
1545 & 549.3 & 4.66 & 45.1 \\
1235 & 548.6 & 3.47 & 33.7 \\
\hline
\end{tabular}

* Based on Reactor Coolant System density 
FIGURE 15

ACCUMULATED LEAKAGE VS. TIME

\# 1 SEAL FAILS, \#2 \& 3 FUNCTION

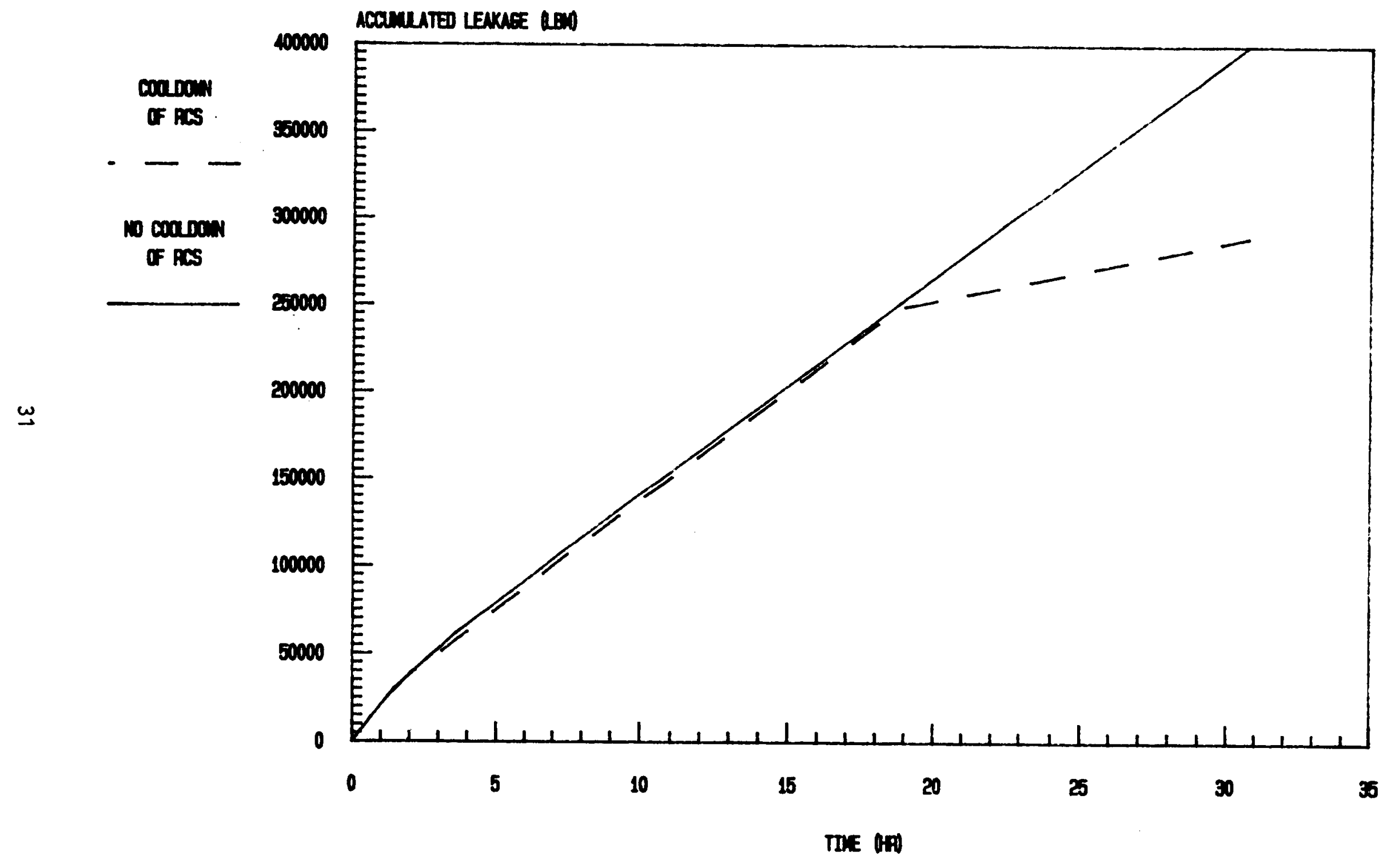




\section{FIGURE 16}

TYPICAL \#1 SEAL LEAKOFF PIPING

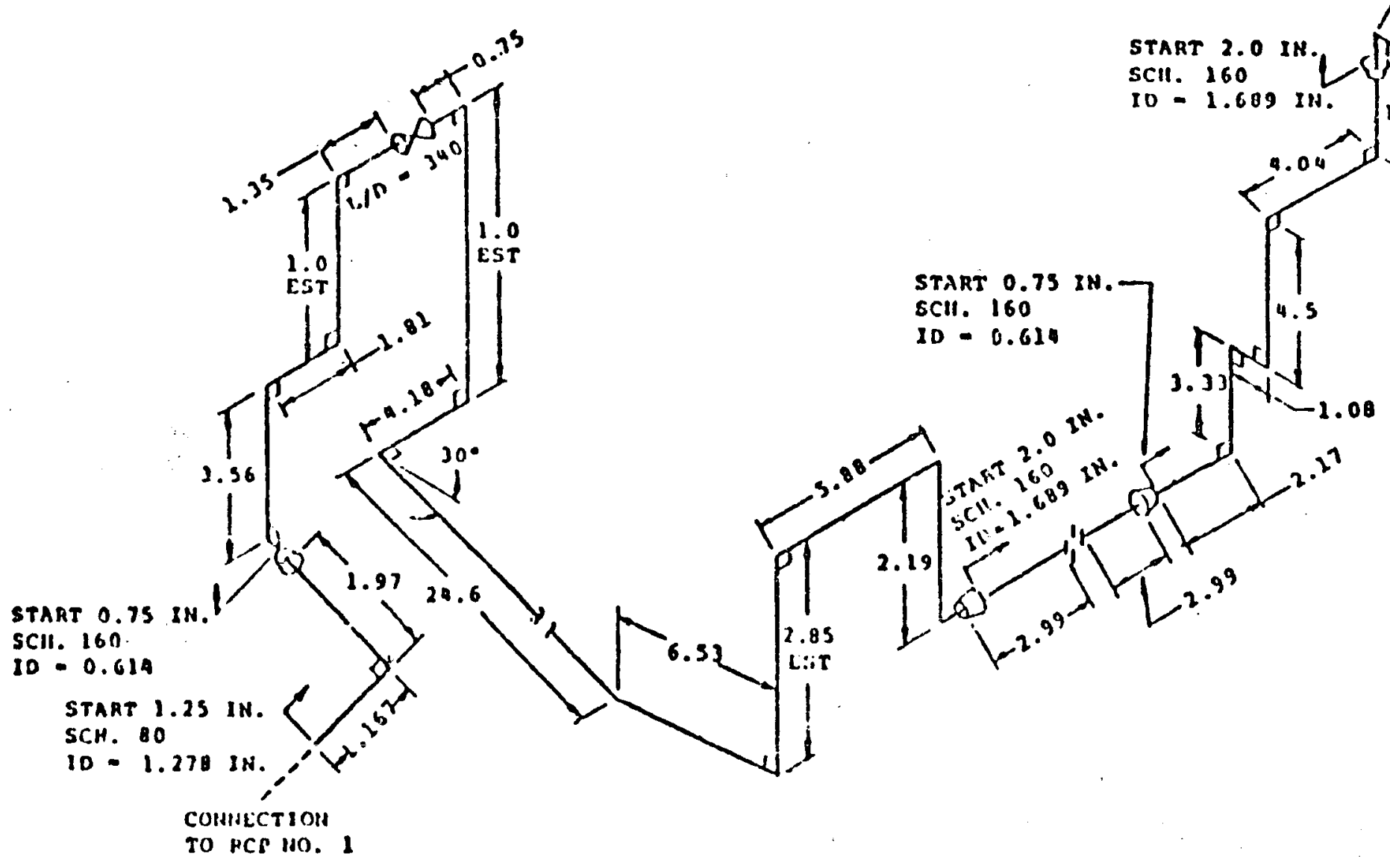

SYIINOI. KCY,

(1) ReDUCER Or txranot:R

ill orifice

a) valve

NOTE,

ALL DIMENSIONS IN TETT 


\section{FIGURE 17}

\section{$\# 1$ SEAL LEAKOFF PIPING}

WI IHOUT FINAL "SECTION OF 2" PIPING

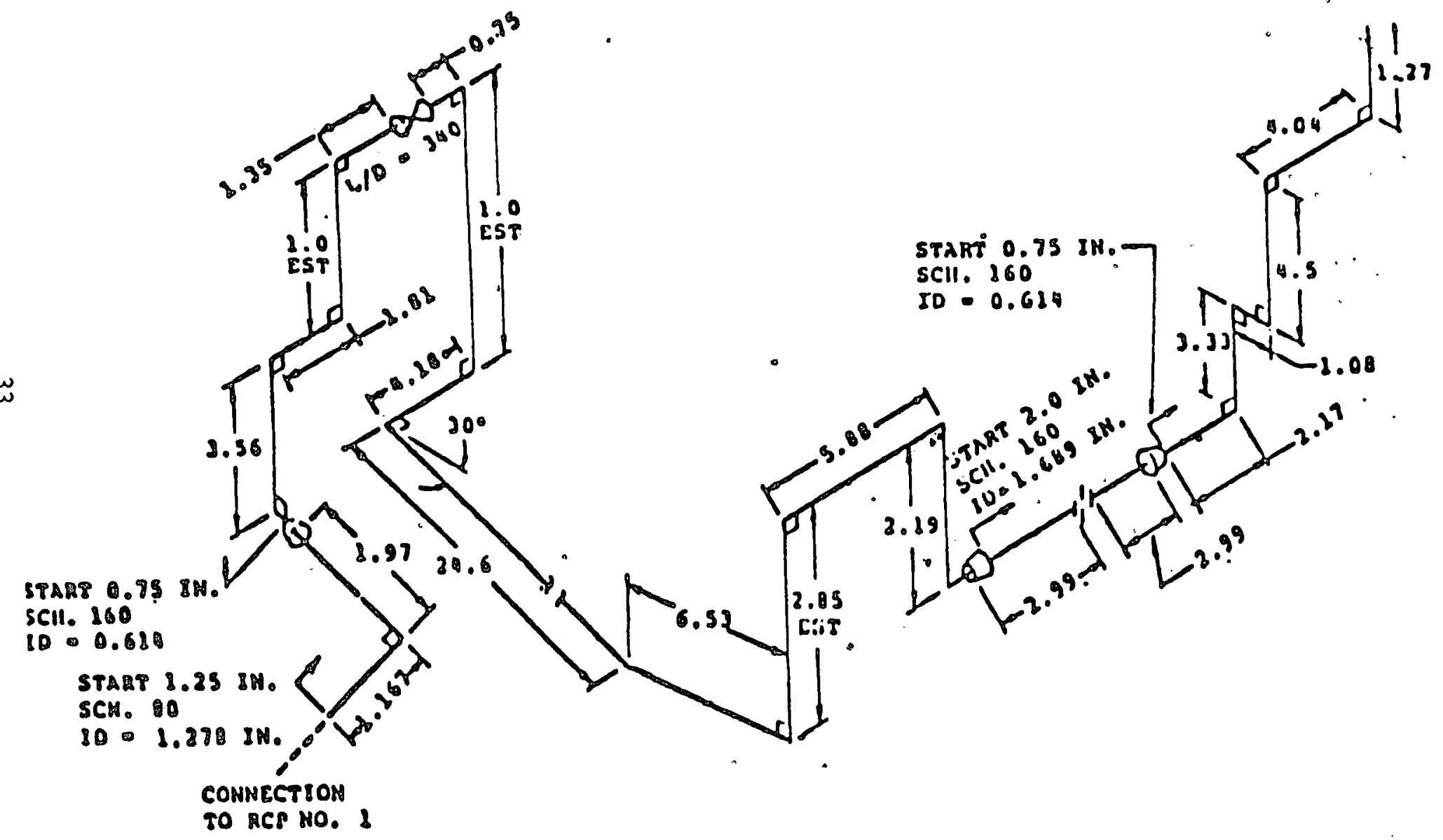




\section{FIGURE 18}

\section{$\# 1$ SEAL LEAKOFF PIPING}

WITHOUT FINAL SECTION OF .75" PIPING

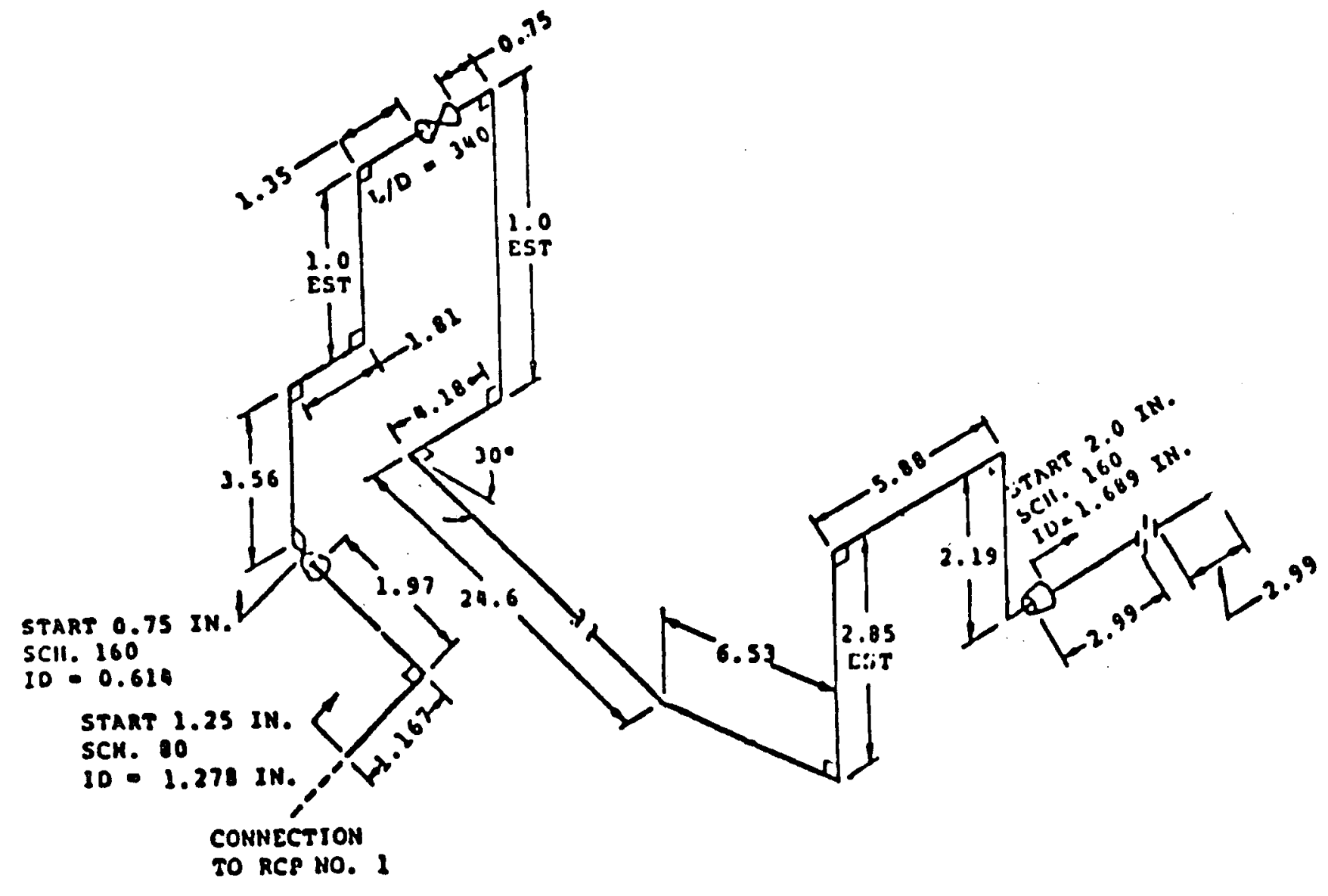




\section{FIGURE 19 \\ LEAKAGE VS. \#1 LEAKOFF LINE RESISTANCE}

\section{LEGUE RATE REVSEC}

\section{SELL FATLS L250 PSIA $500 \mathrm{~F}$}

10

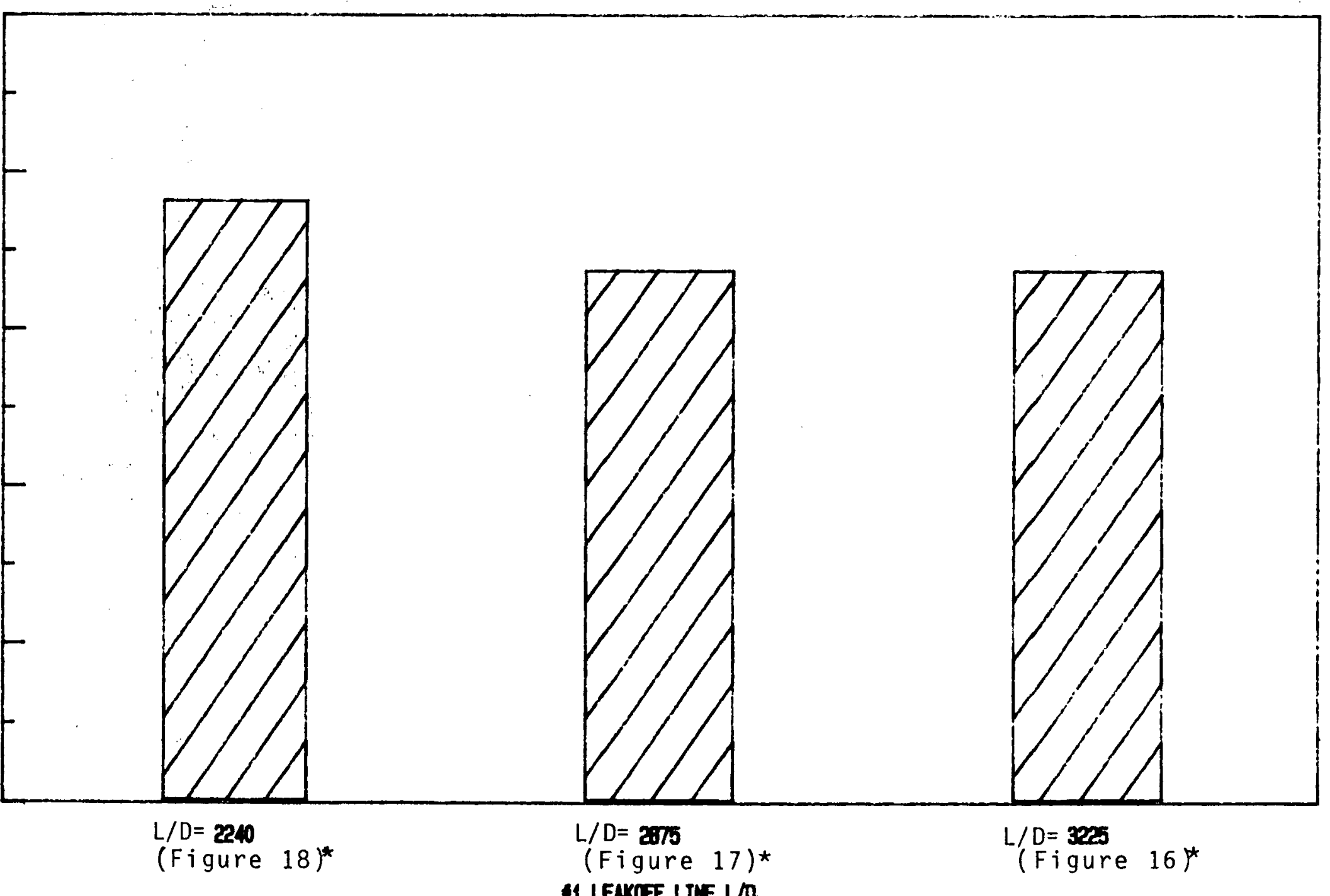

*Figure number gives isometric corresponding to leakoff line L/D 
When all three seals fail the primary leakage path is through the open no. 1 , 2 and 3 seals and out the top of the pump casing. This flow path offers less resistance to flow than the alternate leak paths; the no. 1,2 and 3 leakoff lines. The controlling resistance for this case is the labyrinth seal. ETEC predicts flow will choke at this point and therefore the downstream flow path will not affect the leakage rate.

\subsubsection{RCS Cooldown and Depressurization}

No attempt was made to calculate accumulated leakage versus time for the case in which all three seals fail. For this case the initial leak rate is more than 20 times greater than the leak rate when all seals function. The RCS will drain and depressurize faster when all three seals fail. Because of the large discrepancy between the leakage rates for the two cases, the error in using the RCS pressure and temperature histories render the results almost meaningless.

\subsubsection{Sensitivity Studies}

In the case in which all three seals fail, the dominant resistance factor is the labyrinth seal at the seal assembly inlet. A pressure drop of approximately 1235 psia is predicted across this seal. It is also predicted that flow will choke at this point. Three different resistance, or $K$, factors were used to determine the sensitivity of leakage rate to this paramater. The lowest $K$ factor (4.7) corresponds to that used by Westinghouse in their. analysis. During a meeting between ETEC and Westinghouse, ETEC was informed that this low $\mathrm{K}$ factor was calculated based only on entrance and exit losses. The highest $K$ factor (15.4) corresponds to the resistance factor reported by Westinghouse during a February 28, 1984 meeting on RCP seals. The third K. factor (10.0) is an average of the two values. Figure 20 illustrates the variation in leakage rate with labyrinth seal $\mathrm{K}$ factor. All cases were run with reactor coolant pressure of 2250 psia and temperature of $550^{\circ} \mathrm{F}$. As shown on Figure 20, a lower $K$ factor results in a larger leak rate. Therefore, ETEC chose to use the $K$ factor of 4.7 for their analysis as it gave the most conservative results.

To verify that the ETEC assumption was conservative, that is that the true labyrinth seal $K$ factor is not less than 4.7, ETEC made an independent calculation of the labyrinth seal $K$ factor based on proprietary drawings of the Westinghouse RCP. The labyrinth was approximated as a small annulus between the shaft outside diameter and the inner edge of the labyrinth seal. The calculated resistance factor was slightly greater than 4.7 , indicating that the $K$ factor of 4.7 used in the ETEC and Westinghouse analyses is less than the true labyrinth seal resistance factor. Thus, the leak rates calculated by ETEC and Westinghouse for the case in which all seals fail are conservative. Since labyrinth seal resistance can not be accurately calculated, the recommendations (Section 4) include testing to determine the labyrinth seal hydraulic resistance. 


\section{FIGURE 20}

LEAKAGE VS. LABYRINTH SEAL RESISTANCE

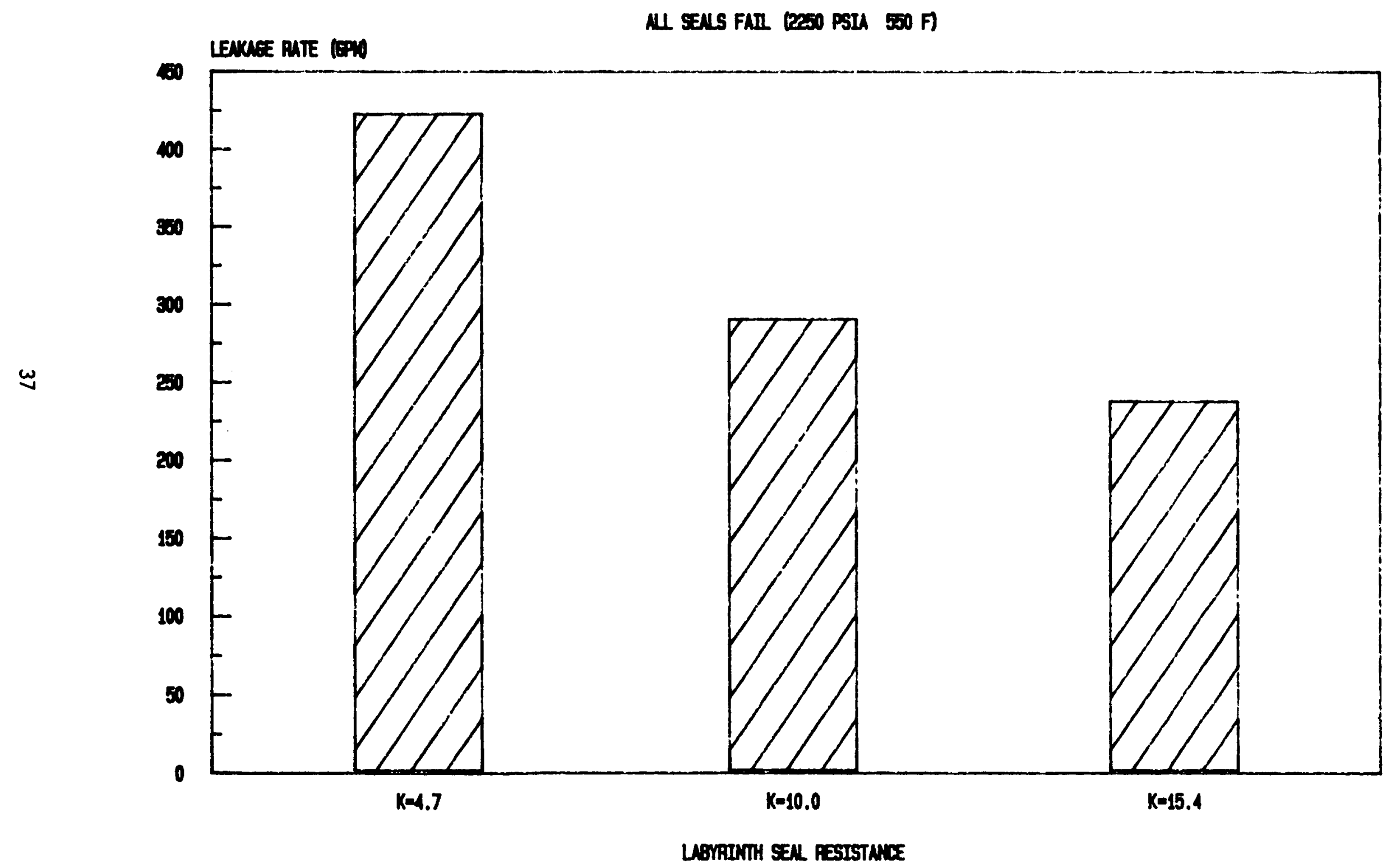




\subsection{O-RING AND CHANNEL SEALS}

As a part of the structural analys is of the no. 1 seal assembly, the change in 0 -ring and channel seal gland gap size was evaluated. No attempt was made to .$e$ determine whether these changes would cause failure or blowout of the 0-rings and channel seals. Table 5 and Figure 21 present the results of this work.

As part of the structural analysis to determine the response of the seals to station blackout conditions, the ANSYS model was used to generate isotherms across the seals. The isotherm plot of the no. 2 seal for $518^{\circ} \mathrm{F}$ upstream and $212^{\circ} \mathrm{F}$ downstream is presented as Figure 22. ETEC used the isotherm plot to check the 0-ring and channel seal temperatures predicted by Westinghouse, Ref. 1. Most of the Westinghouse values appeared reasonable. However, for the channel seal circled on Figure 22, the $240^{\circ} \mathrm{F}$ temperature reported by Westinghouse seemed low. From Figure 22 the average temperature for this channel seal appears to be closer to $340^{\circ} \mathrm{F}$.

\subsection{UNCERTAINTY}

In addition to the effect of the parameters examined in the sensitivity studies, Sections 3.1.3, 3.2.3 and 3.3.3, the analytical correlations also must be considered. The Dukler two-phase flow correlations have a reported uncertainty of $20 \%$, reference 2. However, experience with other two-phase correlations indicate that this uncertainity is probably low. A 50\% uncertainty in the calculated flow rates appears more reasonable. The uncertainty in flow correlations is much greater than that which results from machining tolerances or leakoff line configuration. 
TABLE 5: 0-RING AND CHANNEL SEAL GLAND GAP CHANGES --1 SEAL ASSEMBLY

\begin{tabular}{ccc}
$\begin{array}{c}\text { O-Ring or } \\
\text { Channel Seal }\end{array}$ & $\begin{array}{c}\text { Change Due to } \Delta P \\
(2200 \text { psia to } 30 \text { psia })\end{array}$ & $\begin{array}{c}\text { Change Due to } \Delta T \\
\left(550^{\circ} \mathrm{F} \text { to } 518^{\circ} \mathrm{F}\right)\end{array}$ \\
\hline $1-1$ & $.56 \mathrm{mils}$ closed & $.48 \mathrm{mils}$ open \\
$1-2$ & $.48 \mathrm{mi} / \mathrm{s}$ closed & $.91 \mathrm{mils}$ open \\
$1-3$ & $.16 \mathrm{mils}$ closed & $.79 \mathrm{mils}$ open \\
$1-4$ & $.15 \mathrm{mils}$ open & $.73 \mathrm{mils}$ open \\
$1-5$ & $.02 \mathrm{mils}$ open & $.77 \mathrm{mils}$ open \\
$1-6$ & $.18 \mathrm{mils}$ closed & $.97 \mathrm{mils}$ open \\
$1-7$ & $.4 \mathrm{mils}$ closed & $.84 \mathrm{mils}$ open \\
$1-8$ & $.18 \mathrm{mils}$ open & $.92 \mathrm{mils}$ open \\
\hline
\end{tabular}


FIGURE 21:

\#1 SEAL ASSEMBLY: 0-RING AND CHANNEL SEALS

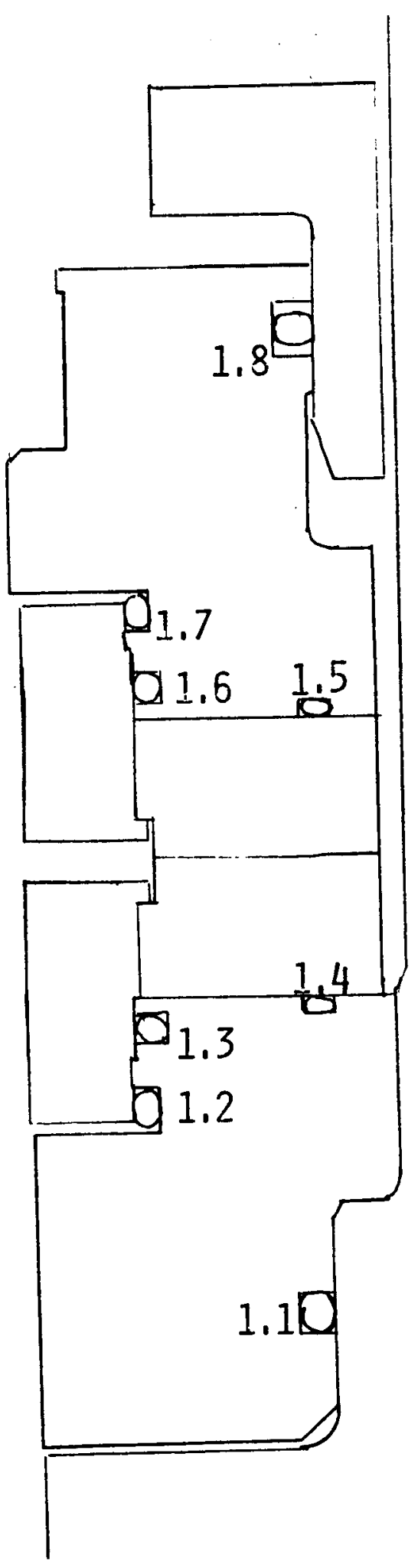


FIGURE 22:

ISOTHERM MAP OF THE \#2 SEAL

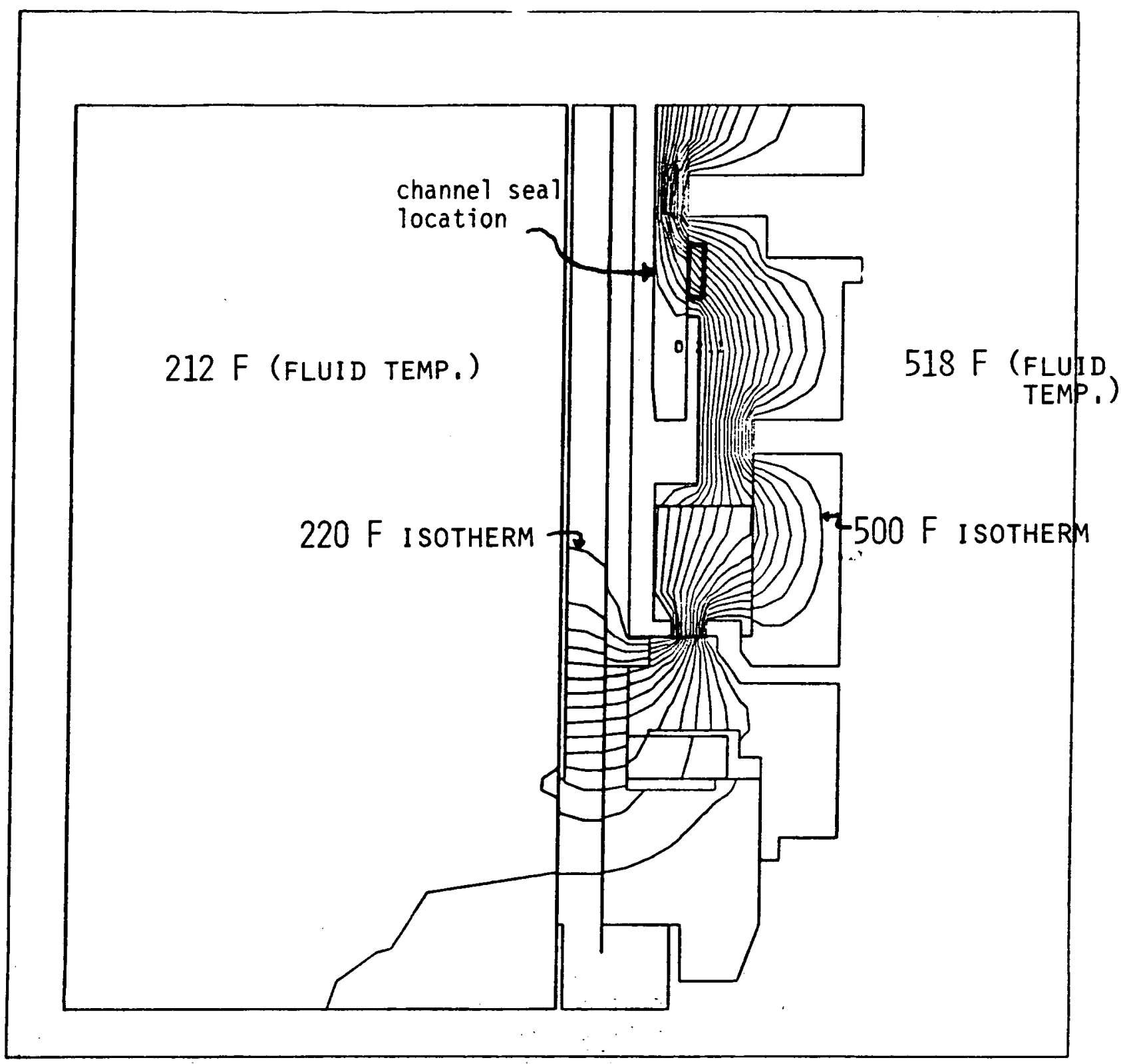




\subsection{CONCLUSIONS AND RECOMMEDATIONS}

The independent ETEC analysis of leakage through the Westinghouse RCP seal assembly confirmed the results of a previous Westinghouse analys is. The results of the two analyses are compared in Table 7.

ETEC evaluated the Westinghouse modeling assumptions and concluded they were reasonable or gave conservative results. The major difference between ETEC and Westinghouse seal models dealt with two-phase flow modeling assumptions. ETEC's constant slip two-phase flow assumption is more realistic and also less conservative than Westinghouse's homogenous flow representation and therefore, ETEC predicted leak rates are generally less than Westinghouse values.

The scope of the ETEC study did not include predicting RCS pressure and temperature conditions after initial station blackout. ETEC used the RCS conditions predicted by Westinghouse for a 'typical four loop plant', see reference 1. Westinghouse predicted RCS conditions based on two assumptions: (1) operators initiated reactor cooldown procedures and (2) operators failed to initiate cooldown procedures. Operator initiated cooldown of the RCS significantly reduced accumulated leakage during station blackout, see figures 10 and 11. The Westinghouse calculations of RCS cooldown, presented in reference 1, were reviewed by ETEC and appear reasonable. However, since cooldown has a significant impact on accumulated leakage, these calculations should be verified.

The following recommendations are made regarding future investigation.

1. Determine Experimentally the Probability of Seal Failure

Analys is indicates that seal failure is an important factor in determining the time required to uncover the core. The probability of seal failure cannot be accurately determined by analysis, therefore the probability of seal failure should be determined experimentally.

2. Evaluate the Effect of Boil-off Downstream of No. 2 Seal

ETEC and Westinghouse analyses predict that the temperature gradient across the No. 2 seal will cause it to rotate closed during a station blackout. However, if all the water downstream of the no. 2 seal flashes to steam and "boils-off," the heat sink provided by the water will be lost and the temperature gradient across the no. 2 seal will decrease. The predicted leakage rate is close to the boil-off rate, therefore an analysis of the no. 2 seal, assuming boil-off, would provide valuable information on seal stability and closure.

3. Determine Experimentally the Labyrinth Seal Flow Resistance

The dominant resistance for the case when all three seals fail is the labyrinth seal located between the impeller and the first stage seal. To identify the worst case leakage rate when all three seals fail open, the resistance factor for the labyrinth sould be determined experimentally. 
TABLE 6: LEAKAGE RATES AT INITIAL REACTOR COOLANT

SYSTEM CONDITIONS (2250 psia, 550 F)

\begin{tabular}{lcccccc}
\hline & Seal & & \multicolumn{2}{c}{ ETEC } & \multicolumn{2}{c}{ Westinghouse } \\
$\# 1$ & $\# 2$ & $\# 3$ & $(1 \mathrm{~b} / \mathrm{sec})$ & $(\mathrm{gpm})$ & $(1 \mathrm{bm} / \mathrm{sec})$ & $(\mathrm{gpm})$ \\
\hline FN & FN & FN & 2.05 & 19.6 & 2.20 & 21.1 \\
FAIL & FN & FN & 6.76 & 64.7 & 7.90 & 75.6 \\
FAIL & FAIL & FAIL & 44.1 & 422 & 50.2 & 480 \\
\hline
\end{tabular}

$F N=$ Function

FAIL = Fail Open 
4. Evaluate Time to Uncover Core for Specific Plants

An important result of the leakage rate analys is is the time required to uncover the core. This time should be determined for specific plants based on their individual system thermal hydraulic response characteristics and hardware designs.

5. Evaluate No: 2 Seal Leakage with Failure of No. 1 Seal

Analysis indicates that the no. 2 seal will rotate closed during a station blackout due to thermal gradients across the seal. This behavior limits the overall leak rate, especially if the no. 1 seal fails open. As presented in section 3.2.1, the calculated leak rate past the no. 2 seal when it rotates closed is on the order of $.1 \mathrm{gpm}$. However, analys is can not verify whether the no. 2 seal can withstand full system pressure and high temperature gradients for an extended time period. Therefore, testing of the no. 2 seal subjected to these conditions--preferrably during a test of a full scale seal assembly-is recommended. If testing of a RCP seal assembly is not conducted, then tests of the 0-rings and channel seals, under pressure and temperature conditions which would exist if the no. 1 seal failed, should be considered. 


\section{REFERENCES}

1. Westinghouse Owners Group Report, WCAP 10541, "Reactor Coolant Pump Seal Performance Following a Loss of all AC Power", April 1984.

2. "Chemical Engineering Aspects of Two-Phase Flow", A. E. DeGance and R. W. Atherton, Chemical Engineering Vol. 77, March 23, 1970 February 22, 1971.

3. ANSYS, Swanson Analys is Systems, Inc., Rev. 4.0, 1982. 
APPENDIX A

SEAL FORCE BALANCE MODEL

1.0 RADIAL FLOW BETWEEN CONVERGING/DIVERGING ANNULAR PLATES (GENERAL SOLUTION)

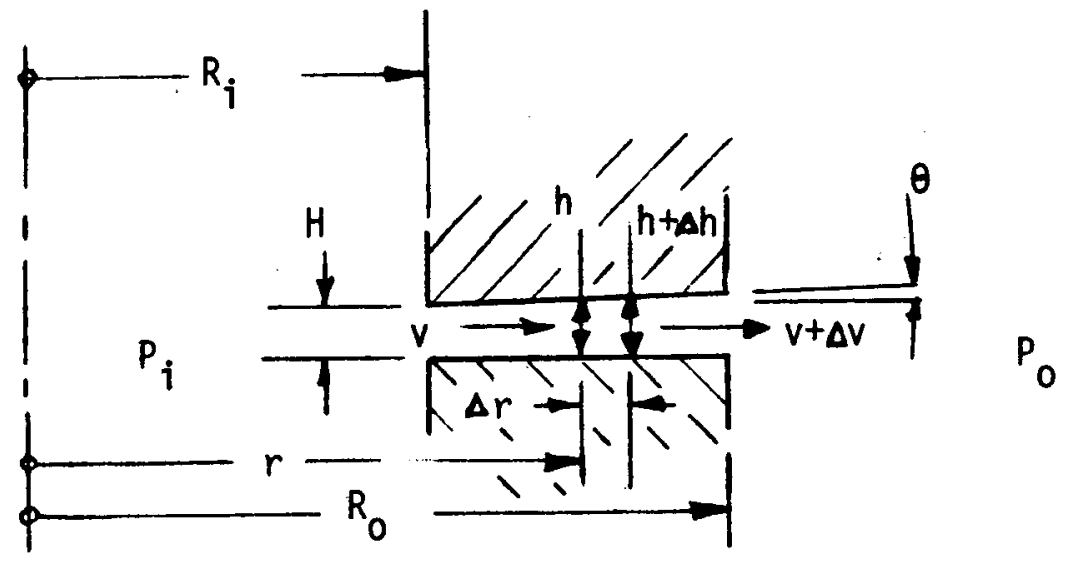

$\mathrm{d}_{\text {eq }}$ Equivalent diameter, local [= $\left.2 \mathrm{~h}\right]$

in.

f Friction factor, local

g Gravitational constant

$h$ Gap between plates, local

H Gap between plates at inner radius

$K$ Pressure loss factor (entrance or exit)

p Pressure, local

$P$ Pressure, inlet or outlet

Q Volumetric flowrate

$r$ Radius, local

$R$ Radius, inlet or outlet

Re Reynolds number

$v \quad$ Velocity, local

$v$ Velocity, inlet or outlet

$w \quad$ Fluid specific weight

$\triangle \quad$ Denotes change

$\theta \quad$ Included angle between plates

$\mu \quad$ Absolute viscosity of fluid

in $/ \sec ^{2}$

in.

in.

$\bar{b} /$ in $^{2}$

$1 b /$ in $^{2}$

in $^{3} / \mathrm{sec}$

in.

in.

$-$

$\mathrm{in} / \mathrm{sec}$

in/ sec

lb/ in 3

$($ radians)

\section{Subscripts:}

i Inner Radius of Seal Face

- Outer Radius of Seal Face

1 Inner Radius of Seal Face Downs-ream of Chamfer

2 Radius of Seal Face at Which Included Angle

3 Outer Radius of Seal Face Upstream of Chamfer

4 Radius at Which Sliding O-Ring is Located 


\subsection{GENERAL SOLUTION}

A. Local gap between plates $(h)$

$$
\begin{gathered}
h=H+\left(r-R_{i}\right) \theta \quad \text { Where the small angle approximation } \\
(\theta=\tan \theta) \text { is assumed }
\end{gathered}
$$

B. Local velocity between plates ( $v$ )

$$
\begin{aligned}
& v=Q / 2 \pi r h \\
& v=\frac{Q}{2 \pi r\left[H+\left(r-R_{j}\right) \theta\right]}
\end{aligned}
$$

C. Local pressure gradient $(\Delta p / \Delta r)$

$$
\begin{aligned}
& \frac{\Delta p}{\Delta r}=\left(\frac{\Delta p}{\Delta r}\right)_{1}+\left(\frac{\Delta p}{\Delta r}\right)_{2} \\
& \text { Where }(\Delta p / \Delta r)_{1}=\text { Pressure gradient due to } \\
& \text { fluid friction } \\
& (\Delta p / \Delta r)_{2}=\text { Pressure gradient due to } \\
& \text { velocity change }
\end{aligned}
$$

C.1 Friction pressure gradient

$$
\left(\frac{\Delta p}{\Delta r}\right)_{1}=-w \frac{f}{D_{e q}} \cdot \frac{v^{2}}{2 g}
$$

For flow through parallel plates, $D_{e q}=2 h$

$$
\begin{aligned}
& =\frac{-w f}{4 g h}\left(\frac{Q}{2 \pi r h}\right)^{2} \\
\frac{\Delta p_{1}}{\Delta r_{1}} & =-\frac{w f Q}{16 \pi^{2} g}{ }^{2}\left\{\frac{1}{r^{2}\left[H+\left(r-R_{j}\right) \theta\right]^{3}}\right\}
\end{aligned}
$$

NOTE: The above equation indicates a negative pressure gradient (pressure decreases with radius) based on the initial assumption of radial outflow. For radial inflow, the sign of the gradient is reversed. 
C.2 Velocity pressure gradient

$$
\begin{aligned}
& \left(\frac{\Delta p}{\Delta r}\right)_{2}=-\frac{w}{\Delta r} \cdot \Delta\left(\frac{v^{2}}{2 g}\right)=-\frac{w}{\Delta r} \cdot \frac{(v+\Delta v)^{2}-(v)^{2}}{2 g} \\
& \left(\frac{\Delta p}{\Delta r_{2}}\right)=-\frac{w}{g}\left(\frac{v: \Delta v}{\Delta r}\right) \begin{array}{l}
\text { where the term }(\Delta v)^{2} \text { in the expansion is assumed } \\
\text { to be negligable }
\end{array} \\
& v=\frac{Q}{2 \pi r h}, \quad \Delta v=\Delta\left(\frac{Q}{2 \pi r h}\right) \\
& =\frac{-Q \cdot \Delta(2 \pi r h)}{(2 \pi r h)^{2}} \\
& =-\frac{Q \cdot 2 \pi(r \Delta h+h \Delta r)}{(2 \pi r h)^{2}} \\
& \Delta v=-\frac{Q(r \Delta h+h \Delta r)}{2 \pi r^{2} h^{2}} \\
& \text { but: } h=\left[H+\left(r-R_{j}\right) \theta\right] \\
& h=\theta \cdot \Delta r \\
& \Delta v=-\frac{Q(r \theta \cdot \Delta r+h \cdot \Delta r)}{2 \pi r^{2} h^{2}} \\
& \left(\frac{\Delta p}{\Delta r}\right)=-\frac{W}{g}\left(\frac{Q}{2 \pi r h}\right)\left[-\frac{Q(r \theta \cdot \Delta r+h \cdot \Delta r)}{2 \pi r^{2} h^{2} \cdot \Delta r}\right] \\
& =\frac{W Q^{2}}{4 \pi^{2} g}\left[\frac{\theta}{r^{2} h^{3}}+\frac{1}{r^{3} h^{2}}\right] \\
& \left(\frac{\Delta p}{\Delta r}\right)=\frac{w Q^{2}}{4 \pi^{2} g}\left[\frac{\theta}{r^{2}\left[H+\left(r-R_{j}\right) \theta\right]^{3}}+\frac{1}{r^{3}\left[H+\left(r-R_{i}\right) \theta\right]^{2}}\right]
\end{aligned}
$$


C.3 Total pressure gradient $=(\Delta p / \Delta r)_{1}+(\Delta p / \Delta r)_{2}$

$$
\left(\frac{\Delta p}{\Delta r}\right)=\frac{w}{g}\left(\frac{Q}{2 \pi}\right)^{2} \frac{(\theta+.25 f)}{r^{2}\left[H+\left(r-R_{i}\right) \theta\right]^{3}}+\frac{1}{r^{3}\left[H+\left(r-R_{i}\right) \theta\right]^{2}}
$$

D. Entrance and exit loss factors $\left(k_{i}\right.$ and $\left.k_{0}\right)$

Entrance and exit pressure losses are taken as proportional to the local (entrance or exit) velocity head:

$$
\Delta p_{\text {10s }}=\frac{w}{g} k \frac{v^{2}}{2 g}
$$

D.1 Entrance loss factor $\left(K_{0}\right)$

Considering the inlet edge configuration, chamfered or rounded, the inlet loss factor is assumed at one-half the maximum value (0.5) given for a sudden contraction.

$$
\begin{aligned}
& k_{0}=.5 \times 0.5 \\
& k_{0}=0.25
\end{aligned}
$$

\section{D.2 Exit loss factor $\left(K_{i}\right)$}

Under similar consideration, the exit loss factor is assumed at one-half the maximum value (1.0) given for a sudden expansion.

$$
\begin{aligned}
& k_{i}=\frac{1}{2} \times 1.0 \\
& k_{i}=0.5
\end{aligned}
$$

Maximum loss factors are from "Flow of Fluids through Valves, Fittings, and Pipes," by Crane Co. 


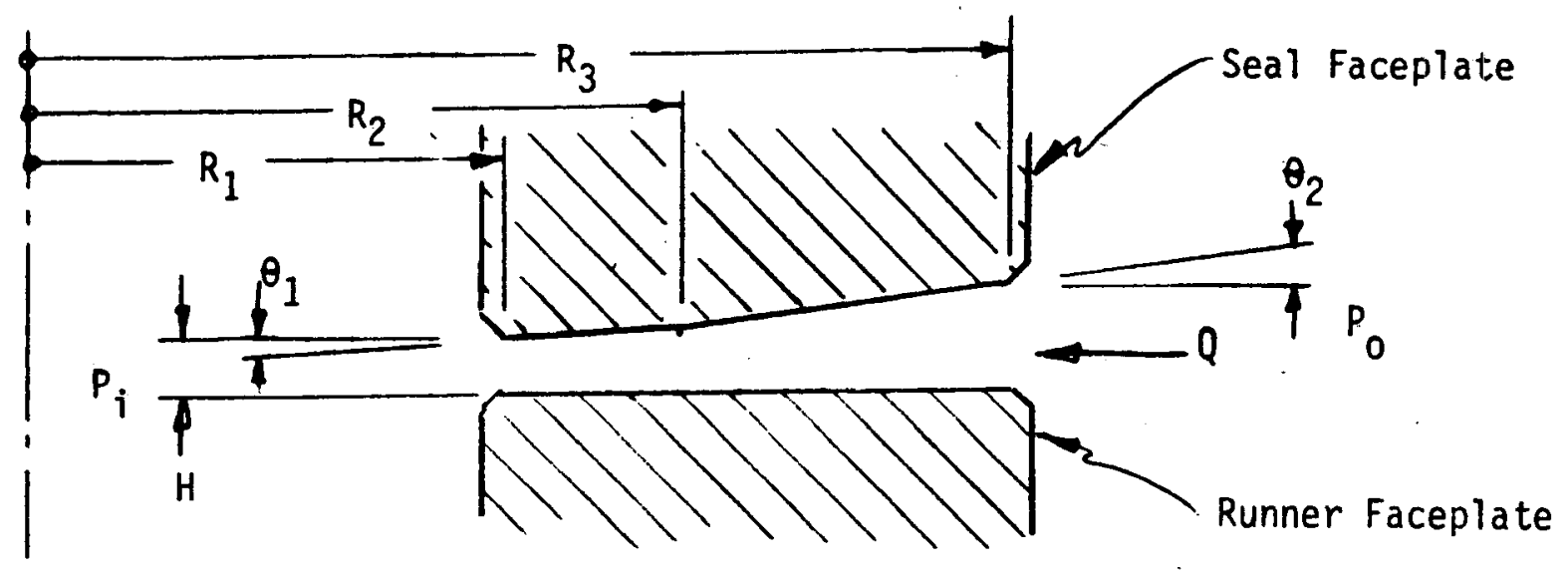

Pressure loss through seal faces

$$
\begin{aligned}
\Delta p= & \frac{w}{g} K_{0}\left\{\frac{W / w}{2 \pi R_{3}\left[H+\left(R_{2}-R_{1}\right) \theta_{1}+\left(R_{3}-R_{2}\right) \theta_{2}\right]}\right\}^{2} \\
& +\frac{w}{g}\left(\frac{W / W}{2 \pi}\right)^{2} \sum_{r=R_{3}}^{r=R_{2}}\left\{\frac{\left(\theta_{2}+.25 f\right)}{r^{2}\left[H+\left(r-R_{2}\right) \theta_{2}+\left(R_{2}-R_{1}\right) \theta_{1}\right]^{3}}\right] \Delta r \\
& +\frac{w}{g}\left(\frac{W / w}{2 \pi}\right)^{2} \quad \sum_{r=R_{2}}^{r}\left\{\frac{\left(H+\left(r-R_{2}\right) \theta_{2}+\left(R_{2}-R_{1}\right) \theta_{1}\right]^{3}}{r^{2}\left[H+\left(r-R_{1}\right) \theta_{1}\right]^{3}}+\frac{1}{r^{3}\left[H+\left(r-R_{1}\right) \theta_{1}\right]^{3}}\right\} \Delta r \\
& +\frac{w}{g} K_{i}\left(\frac{W / w}{2 \pi R_{1} H^{\prime}}\right)^{2}
\end{aligned}
$$

The above difference equation is summed, using a digital computer and $\Delta r$ increments of 0.01 inch. At each step the local Reynolds. number and absolute pressure are evaluated to determine the appropriate friction factor. 


\subsection{SEAL FORCE BALANCE}

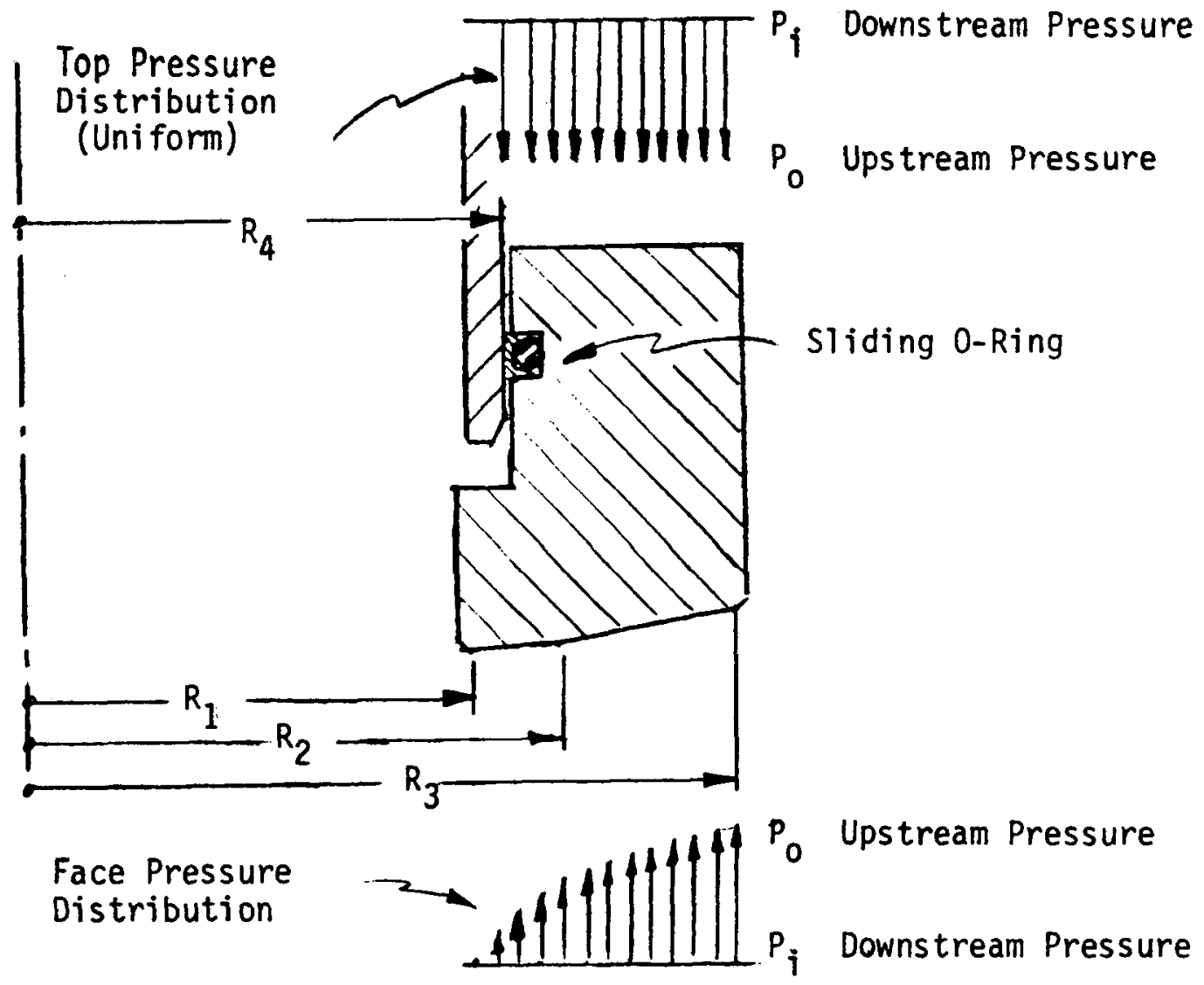

The axial position of the seal (and thus the gap) is stabilized when the force resulting from the face pressure distribution is equal to the force resulting from the top pressure distribution (weight neglected):

$$
\left(P_{0}-P_{i}\right) \pi\left(R_{3}^{2}-R_{4}^{2}\right)=2 \pi \sum_{r=R_{3}}^{r=R_{1}} r\left(p-P_{i}\right) \Delta r
$$

The previous equation is used to generate a pressure function, $p=p(r)$. The downstream pressure, $P_{j}$, is used as the zero reference pressure, i.e., the lowest pressure seen by the seal. The right side of the above equation sums the pressure forces acting on the seal face. Designating this sum as $F_{f}$ and evaluating the area, $\pi\left(R_{3}^{2}-R_{4}^{2}\right)$, from Westinghouse drawings, the above equation may be rewritten as: 


$$
\frac{F_{f}}{\left(P_{0^{-}}-P_{i}\right)}=39.728
$$

which is used as the force balance criterion. Seal performance (pressure drop, temperature difference, and face force/pressure difference ratio) is calculated for various inputs (flow, pressure, temperature) and operation assumptions (minimum gap and face angle). Calculations are performed using logic as shown in the flow diagram in Figure $\mathrm{A}-2$.

Operating conditions which match the force balance criterion on the previous page are further evaluated against structural data, generated to predict seal face rotation (angle between seal faces) resulting from temperature and pressure differences.

Figure $A-1$, shows performance predictions for operating conditions which meet the axial force balance. criterion, assuming single-phase flow with $130^{\circ} \mathrm{F}$ water. Injection water at $130^{\circ} \mathrm{F}$ is supplied to the seal assembly during normal pump operation: This parametric data was calculated to provide. initial information on seal characteristics, to be used as guidance for subsequent detail analyses. 


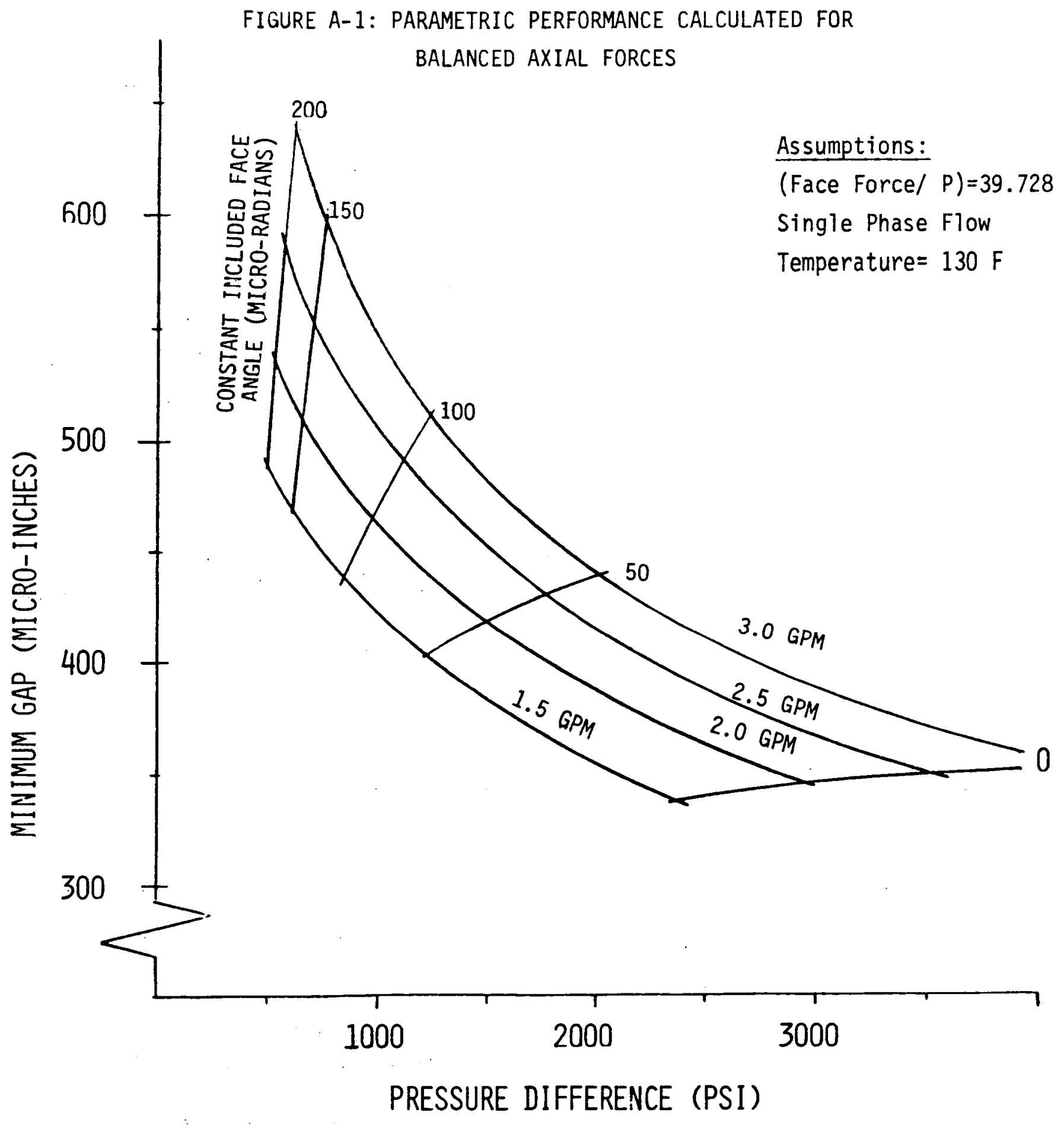


FIGURE A-2

FLOW DIAGRAM FOR SEAL PERFORMANCE CALCULATION

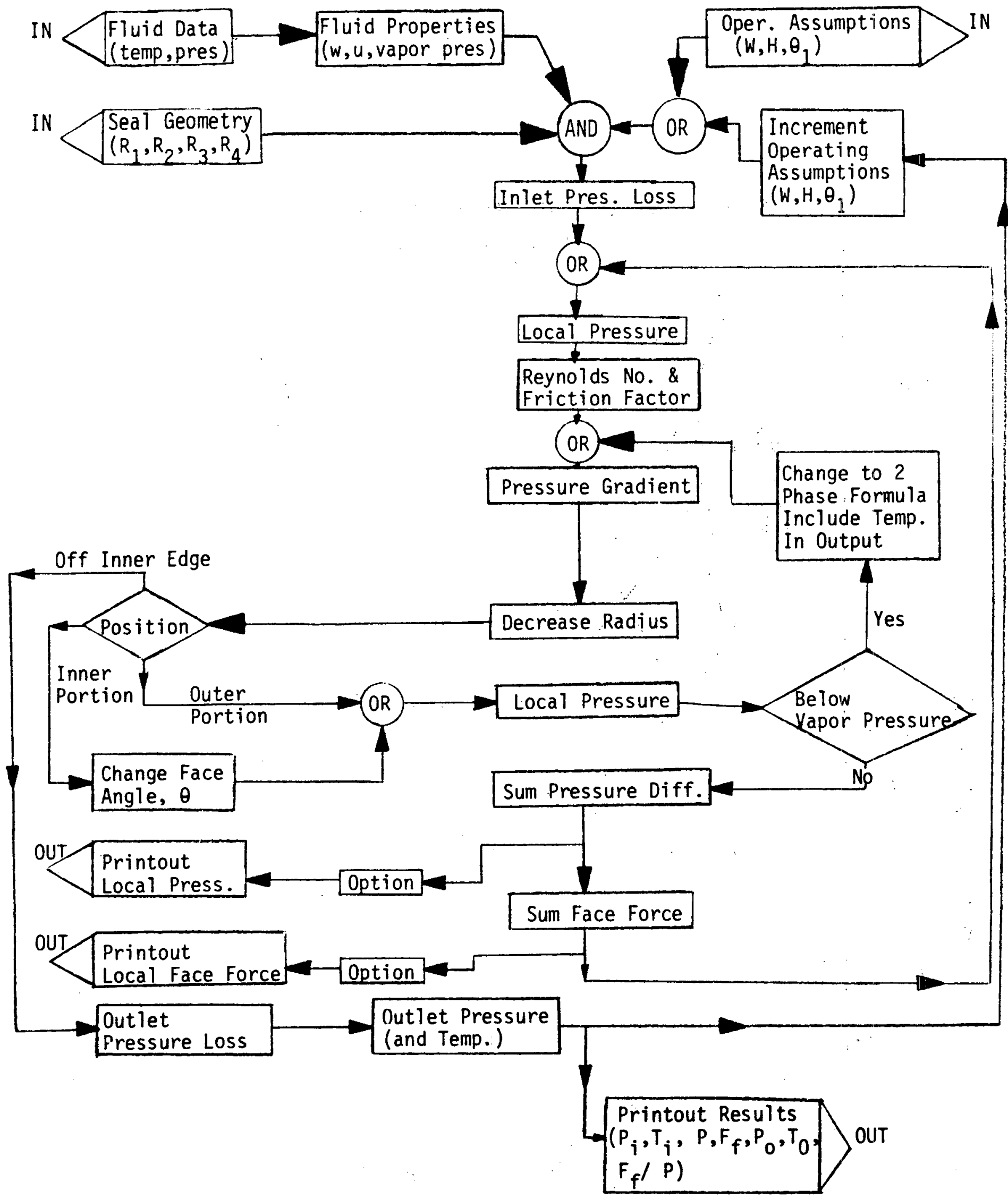


FLOW MODEL

The flow model calculates the pressure drop due to single and two phase flow through the constant area flow paths, such as the labyrinth seal, cartridge seal internals, and the leakoff lines. The two phase flow correlations used are based on the Dutiler constant slip model.

\section{DUFLER TWO FHASE FLOW CONSTANT SLIF MODEL}

The Dukler constant slip, two phase flow model assumes that the ratio of the phase velocities to the average velocity is constant across a cross section. The model does not involve the use of flow regimes, that is the pattern of two phase flow such as bubble, slug, and mist.

\subsection{Terms and Definitions}

A area $(s q f t)$

AC acceleration loss factor

c function of the derivative of steam density with respect to pressure which is used to calculate the acceleration loss factor

d diameter $(f t)$

e surface roughness factor $(f t)$

f two phase friction factor

fo single phase friction factor

$g$ gravitational constant (lbm $f t / 1 b f$ sec sec)

GG superficial mass $f l u x$ of the vapor phase (lbm/sq $f t$ )

GL superficial mass $f l u x$ of the liquid phase (1bm/sq $f t$ )

GT superficial mass $f l u x$ of the two phase fluid ( $1 \mathrm{bm} / \mathrm{sq} f t$ )

K. parameter used in calculating inplace 1 iquid holdup, a function of delta

F pressure (1bf/sq $f t)$

Re Reynolds number

Rg in place vapor holdup, equal to $(1-\mathrm{Kl})$ 


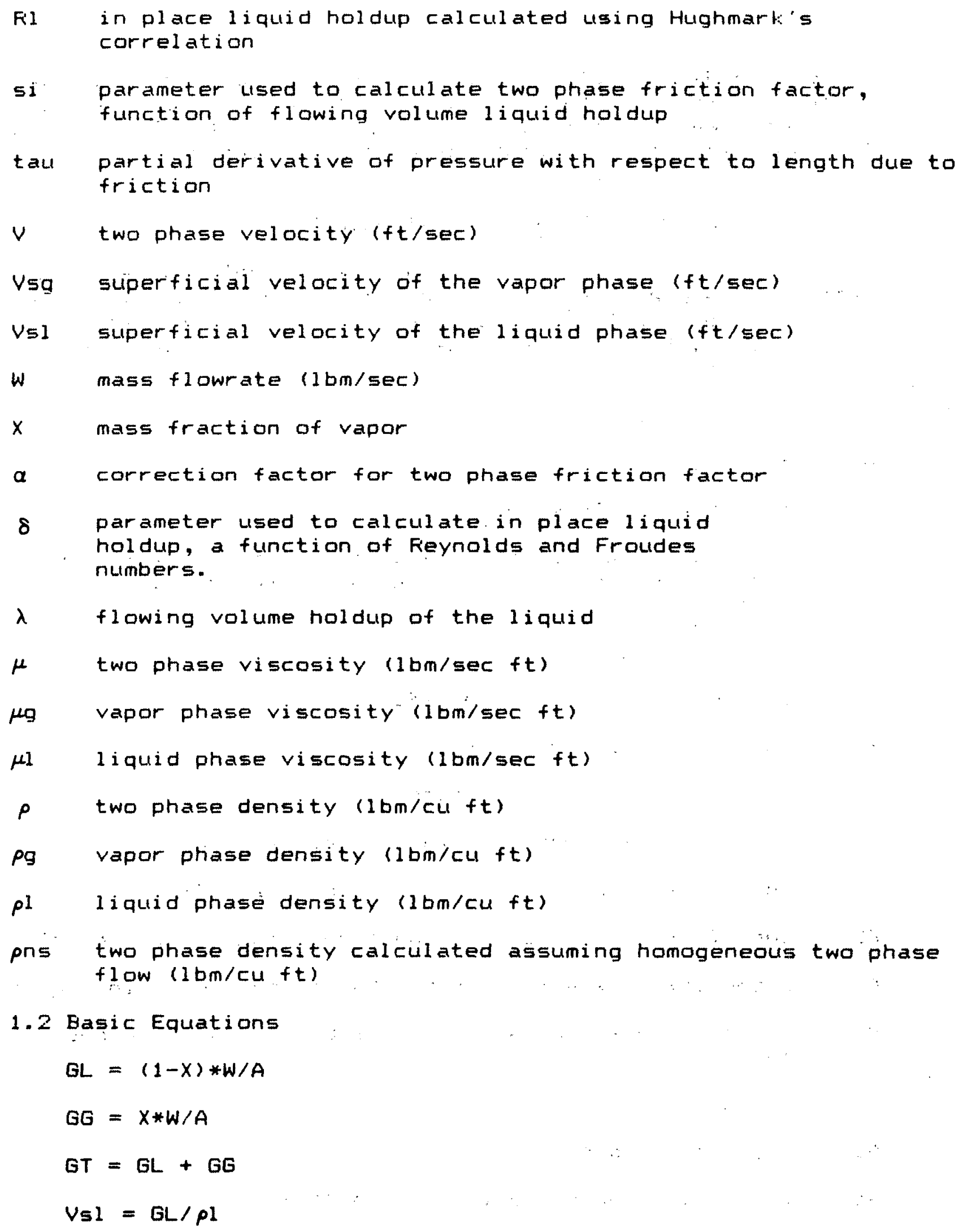

1.2 Basic Equations

$G L=(1-X) * W / A$

$G G=X * W / A$

$G T=G L+G G$

$V s I=G L / \rho 1$ 


$$
\begin{aligned}
& V_{s g}=G G / \rho g \\
& V=V s 1+V s g \\
& \lambda=V \operatorname{si} / V \\
& \mu=\mu l * \lambda+\mu g *(1-\lambda) . \\
& \rho n s=\rho l *+\rho g *(1-\lambda) \\
& \rho=\frac{\rho l * \lambda}{F^{\prime} I}+\frac{\rho g *(1-\lambda)}{\left(1-F^{\prime} I\right)} \\
& \text { Fie }=(p * G T * d) /(\mu * p n s)
\end{aligned}
$$

1. I Two Fhase Friction Factor

$$
f=a * f o
$$

$$
\begin{aligned}
\alpha= & 1-\log (\lambda / s i) \\
s i= & 1.281+.478 * \log \lambda+.444 *(\log \lambda)^{2}+.094 *(\log \lambda)^{3} \\
& +.00843 *(\log \lambda) 4 \\
f o= & .25 *\left[\log \left(e /(3.7 * d)+2.51 /\left(\operatorname{Re} * f \circ 0^{5}\right)\right]^{-2}\right. \\
\operatorname{tau}= & f * \rho * G T /(2 * g * d * \rho n s)
\end{aligned}
$$

1.4 Acceleration Loss Factor

$$
A C=\frac{G L * V s l / F i l+(G G * V s g / F g) *(c-R 1 / F g)}{F * g}
$$

1.5 Hughmark's Correlation for In Flace Liquid Holdup

$$
\begin{aligned}
& \mathrm{R} 1=1-(1-\lambda) * K \\
& \begin{array}{l}
\delta<10 \\
k=.1637-.3104 * \delta+.3525 * \delta^{2}-.001366 * 8^{3}
\end{array} \\
& k^{82}=-.75545-.003585 * 8+.00001436 * \delta^{2} \\
& \delta=\frac{.642 * V \cdot 5_{* G T} .1667 * 0.0427}{V_{s 1} \cdot 25 *\left(F^{1} 1 *(\mu 1-\mu g)+\mu g\right) .1667}
\end{aligned}
$$




\begin{tabular}{|c|c|}
\hline $\begin{array}{l}\text { MAC FOAM } 336 \\
\text { 12.841 } \\
\text { NACM } 1102 . \\
3201,3202 . \\
\text { SEE INSTAUCTIONS ON THE REVERSE. }\end{array}$ & $\begin{array}{l}\text { 1. AEPORT NUMBER (Assigned bV TIOC, odd Vol. No., it anv' } \\
\text { NUREG/CR-4294 } \\
\text { 85-ETEC-DRF-1714 }\end{array}$ \\
\hline 2. TITLE AND SUGTITLE & 3. LEAVE BLANK \\
\hline \multicolumn{2}{|l|}{ Leak Rate Analysis of the Westinghouse Reactor } \\
\hline & 4. DATE REPORT COMPLETED \\
\hline \multirow[t]{2}{*}{ 5. AUTHOA(S) } & January \\
\hline & 6. DATE REPORT ISSUED \\
\hline T. Boardman, N. Jeanmougin, R. Lofaro, J. Prevost & \begin{tabular}{c|c}
\multicolumn{1}{|c|}{ MONTH } & YEAR \\
July & 1985 \\
\end{tabular} \\
\hline 7. PERFORMING ORGANIZATION NAME AND MAILING ADDRESS (Incliude Zip Code) & 8. PROJECT/TASK/WORK UNIT NUMBEA \\
\hline $\begin{array}{l}\text { Energy Technology Engineering Center } \\
\text { Rockwell International Corporation } \\
\text { P. 0. Box } 1449 \\
\text { Canoga Park, CA } 91304\end{array}$ & $\begin{array}{l}\text { 9. FIN OR GRANT NUMBER } \\
\text { B } 3049\end{array}$ \\
\hline 10. SPONSORING ORGANIZATIQN NAME AND MAILING ADDRESS /Include Zip Code/ & 11. TYPE OF REPOAT \\
\hline $\begin{array}{l}\text { Division of Engineering Technology } \\
\text { Office of Nuclear Regulatory Research } \\
\text { U.S. Nuclear Regulatory Commission } \\
\text { Washington, DC } 20555\end{array}$ & $\frac{\text { Technical }}{\text { B. PERIOD COVERED (Inclusive dates) }}$ \\
\hline
\end{tabular}

12. SUPPLEMENTARY NOTES

13. ABSTRACT (200 words or less)

An independent analysis was performed to determine seal leakage rates for the Westinghouse Reactor Coolant Pump (RCP) during a postulated station blackout resulting from loss of ac electric power. The analysis confirmed Westinghouse calculations on RCP seal performance for the three conditions investigated:

(1) all three seals function, (2) No. I seal fails open while Nos. 2 and 3 seals function, and (3) all three seals fail open.

leaks alternating current accident 
UNITED STATES

NUCLEAR REGULATORY COMMISSION

WASHINGTON, D.C. 20555

FOURTH CLASS MAIL POSTAGE \& FEES PAID USNRC

WASH. D.C.

PERMIT No. G-67

OFFICIAL BUSINESS

PENALTY FOR PRIVATE USE, $\$ 300$ 